\title{
Regulation of brain DNA methylation factors and of the orexinergic system by cocaine and food self-administration
}

Lamis Saad $^{1,2}$, Maxime Sartori ${ }^{1,3}$, Sarah Pol Bodetto ${ }^{1}$, Pascal Romieu ${ }^{1}$, Andries Kalsbeek ${ }^{2,4}$, Jean Zwiller ${ }^{1}$ and Patrick Anglard ${ }^{1,5^{*}}$

1. Laboratoire de Neurosciences Cognitives et Adaptatives (LNCA), UMR 7364 CNRS, Université de Strasbourg, Neuropôle de Strasbourg, France.

2. The Netherlands Institute for Neuroscience (NIN), Royal Netherlands Academy of Arts and Sciences (KNAW), Amsterdam, The Netherlands.

3. Present address: IGBMC, Inserm U 964, CNRS UMR 7104, University of Strasbourg, Illkirch, France.

4. Department of Endocrinology and Metabolism, Academic Medical Center (AMC), University of Amsterdam, Amsterdam, Netherlands.

5. INSERM, Institut National de la Santé et de la Recherche Médicale, France.

* Corresponding author: Patrick Anglard, Laboratoire de Neurosciences Cognitives et Adaptatives (LNCA), UMR 7364 CNRS, Université de Strasbourg, INSERM, France

Tel.: 333688519 06; FAX: 33368851958

E-mail: anglard@neuro-cnrs.unistra.fr ; patrick.anglard@inserm.fr, orcid.org/0000-0001-5701-441X

Running title: Differential regulation of DNA methylation and orexin factors by cocaine and food

Key words: cocaine and food self-administration, Drugs of abuse, DNA methylation, epigenetics, orexins/hypocretins, addiction.

\section{Acknowledgments}

This work was supported by the CNRS and the Universite de Strasbourg, by the Neurotime Erasmus + Mundus program of the European Commission including a doctoral fellowship attributed to Lamis Saad. Sarah Pol Bodetto was a former recipient of a fellowship from the 'Ministère de l'Enseignement Supérieur et de la Recherche'. We thank Dr J. Mendoza for kindly providing orexin-A specific antibody and Dr Katia Befort for comments on the manuscript.

\section{Statement of interest}

The authors declare no conflict of interest. 


\begin{abstract}
Inhibitors of DNA methylation and orexin type-1 receptor (orx-R1) antagonists modulate the neurobiological effects driving drugs of abuse and natural reinforcers by activating common brain structures of the mesolimbic reward system. In this study, we applied training procedures to assess the involvement of factors regulating DNA methylation/demethylation processes and satiety or appetite signals. These factors include Dnmts and Tets, miR-212/132, orexins and orx-R1 genes. The study was focussed on dopamine brain projection areas in the prefrontal cortex $(\mathrm{PFCx})$ caudate putamen $(\mathrm{CPu})$ and on the hypothalamus $(\mathrm{HP})$ that is interconnected with the reward system. Striking changes were observed in response to both reinforcers, but differed depending on passive or voluntary intake, feeding conditions and from one brain structure to another. Unexpectedly, orx mRNAs were found in the $\mathrm{CPu}$, but not in the PFCx, indicating a selective transport regulation from their transcription site in the HP. In addition, the orx-Rlgene was found to be induced by cocaine only in the PFCx consistent with its DNA hypomethylation. Together our data demonstrate that DNA methylation/demethylation processes are differentially altered by cocaine and food thereby providing new insights into the mechanism by which each factor triggers its effects. They are also consistent with the distribution of 5-methylcytosine and their oxidative derivatives that differ in their potential contribution to drive long lasting behaviors. Finally, at the molecular level, the current results further support the concept that neural circuits activated by both reinforcers do not completely overlap, as suggested by fMRI and electrophysiological studies.
\end{abstract}




\section{Introduction}

While drugs of abuse and natural reinforcers, such as food or sugar activate common brain structures of the mesolimbic reward system, it is still not clear whether their activated neural circuits completely overlap or not. As illustrated by electrophysiological studies, neurons exhibit non-overlapping firing patterns in response to cocaine vs. sucrose [1-4]. Both reinforcers also induce significant differences in the reactivity of reward brain structures after long-term self-administration, as illustrated by functional magnetic resonance imaging, suggesting the development of neuroadaptative mechanisms related to the emergence of addiction-like behavior occurring only in cocaine self-administering rats [5]. Other studies have reported that neuropeptides modulating feeding and drug reward increase ventral tegmental area (VTA) dopamine neuron firing and responses to both drugs of abuse and food. Nevertheless, there are clearly more complex interactions over-ruling this relationship, since some of them like opioids, orexin (hypocretin), ghrelin, NPY (AgRP) show similar behavioral effects on food intake and cocaine reward, whereas other like CART or Galanin do not [6].

In addition, agents modulating histone acetylation or DNA methylation affect cocaineinduced behavior, but not the intake induced by natural reinforcers in experimental rodent models. Indeed, HDAC inhibitors reduce cocaine self-administration without affecting sucrose self-administration or preference [7]. Treatment with methionine, a methyl donor increasing DNA methylation, inhibits the establishment of cocaine, but not food conditioned place preference [8]. It also reduces cocaine-induced locomotor sensitization and seeking without affecting sucrose self-administration [9]. These studies support the concept that epigenetic regulation of gene expression is part of the responses of brain cells to repeated exposure to drugs of abuse [10-12]. It is also consistent with data showing that repeated cocaine administration modulates the expression of Methyl-DNA Binding Proteins [13,14] and DNA methyltransferases (DNMTs) [15-17]. Drugs of abuse also induce alterations in brain DNA methylation, as observed for specific genes, some of them being involved in learning and memory processes $[18,15,17]$, but also in global $[8,19]$ or genome-wide DNA methylation studies [20,21], showing that gene hypermethylation and hypomethylation simultaneously occur in response to drugs of abuse. Conversely, that DNA methylation contributes to the rewarding effects of cocaine has been well illustrated by manipulating the expression or the activity of MeCP2, mir-212 [14], Dnmt3a [16] and by using methyl donors such as methionine, S-Adenosyl-Methionine (SAM) or DNMT inhibitors [22,23,11], for review.

Following excessive intake, cocaine or food reward may ultimately lead to persistent habits or phenotype effects, but the aforementioned studies did not address how they differ in regulating epigenetic mechanisms involving DNA methylation. We hypothesize that DNA methylation and demethylation processes triggered by each of the two reinforcers could lead to stable long-lasting changes contributing to different addictive-like behaviors. Thus, one aim of the present study was to compare the effect of cocaine with that of food delivery by using a self-administration paradigm in rats exposed to the same schedule of reinforcement. In addition, passive administration was compared with voluntary administration representing a valid model for aspects of human drug addiction [24]. Expression of genes playing a major role in DNA methylation like Dnmt and Tet genes was investigated in the prefrontal cortex $(\mathrm{PFCx})$ and the caudate putamen $(\mathrm{CPu})$. Based on reported homeostatic interactions between Mecp2 and mir-212 [14], a microRNA together with mir-132 belonging to the same intronic cluster activated by CREB [25] were also analyzed.

Since orexinergic neurons project throughout the mesolimbic reward system and play a major role in arousal, feeding behavior/satiety, anxiety and addictive behaviors [26-28], the orexinergic system was also investigated in response to both reinforcers. Expression of the 
orexin-receptor-1 was evaluated in the PFCx and the $\mathrm{CPu}$, since its antagonists, similar to methyl donors, inhibit cocaine self-administration in preclinical trials [29-36]. Orexin expression itself was also examined in both brain structures as well as in the hypothalamus where it is transcribed/synthesized. Since in operant conditioning for food-self delivery food restriction is required, we also analyzed the effect of food restriction itself, with the general aim of better understanding the molecular mechanisms triggered by each reward in specific neuroadaptations.

\section{Materials and methods}

\section{Animals}

Male Wistar rats (Janvier, France), weighting 160-180 g, were housed individually in standard home cages, in a temperature- and humidity-controlled room, under an inverted $12 \mathrm{~h} / 12 \mathrm{~h}$ light/dark cycle (lights on at 7:00 PM). Animals were allowed to acclimate to laboratory conditions and were handled during one week before experimental procedures. Each behavioral experiment started 3 weeks after their arrival in the laboratory and was conducted during the dark period. Animals used for the cocaine operant self-administration experiment had ad libitum access to food and water, whereas animals used for the food pellet operant selfadministration experiment had ad libitum access to water, but were food restricted. Their body weight was progressively reduced to $85 \%$ of its free-feeding value. It was maintained at this level throughout the experiment by providing an individually adjusted amount of food after each daily test session. All procedures involving animal care were conducted in compliance with national laws and policies (Council directive 87848, 1987, Service Vétérinaire de la Santé et de la Protection animale, permission 67-165 to J.Z. and 67-370 to P.R.), with the Ministère de l'Education Nationale de l'Enseignement Supérieur et de la Recherche (project permission number APAFIS\#2133-2015100221087072 to P.A.) and international guidelines (NIH publication 5586-23, 1985). A total of 72 rats has been used in the present study not including the genomic DNA methylation analysis [20].

\section{Surgery, apparatus and cocaine operant self-administration}

Surgical implantation of a chronic indwelling catheter in the jugular vein was performed 10 days after the arrival of the rats in the laboratory. The intravenous (i.v.) catheterization procedure was performed as described previously [7]. After surgery, animals were allowed to recover for 7-10 days before the beginning of the cocaine operant self-administration procedure. Nose pokes (NPs) into both holes were recorded. One hole was selected as the active hole for delivering either the cocaine or the saline solution depending on the experimental group considered and the other as the inactive hole. They were counterbalanced between right and left position in each experimental group and in the various groups of rats. Rats were divided into three experimental groups. A first group of rats self-administering cocaine, called 'SA cocaine' was compared to two yoked groups. Each rat from the two yoked groups was paired with a rat from the 'SA cocaine' group and received passively i.v. injections of either cocaine ('Yoked cocaine' group) or saline ('Yoked $\mathrm{NaCl}$ ' group). These passive injections together with their associated cues were computer-delivered, independently of the rat's behavior and strictly following the number and timing of those determined by the NPs responses of the 'SA cocaine' paired rat. For the 'SA cocaine' group, NPs into the inactive hole (NPi) had no programmed consequence. When the required number of NPs into the active hole was reached, a $40 \mu \mathrm{l}$ cocaine (Cooper, Melun, France) solution $(0.33 \mathrm{mg} / \mathrm{kg}$ diluted in $0.9 \% \mathrm{NaCl}$ ) was delivered by i.v. injection for $2 \mathrm{~s}$ under the control of the 
computer. A stimulus light, located $20 \mathrm{~cm}$ above the active hole, was paired contingently with the delivery of cocaine (light on during $5 \mathrm{~s}$ ), and then turned off, replaced by the house-light of the operant chamber, which materialized a $40 \mathrm{~s}$ time-out period. 'SA cocaine' rats were first submitted to a fixed-ratio 1 (FR1) schedule of reinforcement during daily $2 \mathrm{~h}$ sessions for 4 days. Rats were then submitted to a FR5 schedule of reinforcement during daily $2 \mathrm{~h}$ sessions for 6 days (Fig. 1). No cutoff was applied concerning the number of self-infusions the rat was able to perform during each session.

\section{Apparatus and food pellets operant self-administration procedure.}

Dark five-choice operant chambers $(25.2 \times 28$ × $24 \mathrm{~cm}$, Bioseb, BP 8992370 Chaville, France) placed in sound-attenuated and ventilated enclosures were used to test food pellets operant self-delivery. The curved rear wall comprised nine contiguous $2.3 \mathrm{~cm}$ square holes, located $2.2 \mathrm{~cm}$ above the grid floor. Each hole was equipped with an infrared photocell beam to detect NPs. The two farthest holes were used as the active and the inactive holes, the other holes being obstructed by a metal cover. NPs into both open holes were recorded. The active and inactive holes were counterbalanced between right and left position in each experimental group and in the various groups of rats. The active hole was associated with the delivery of a food pellet (45 mg, Bioserv) into a magazine located at the opposite side of the chamber and equidistant from each hole. The rat collected the delivered food pellet by pushing a Perspex panel covering the magazine. Each chamber was automatically controlled by Packwin software (Panlab S.P., Cornella, Barcelona, Spain).

As for the cocaine experiments, rats were divided into three different groups: 'SA pellets', 'Yoked pellets' and 'Yoked control'. 'SA pellets' and 'Yoked pellets' rats were initially given access to food pellets in their home cage (10 pellets per day during 5 consecutive days) to get them used to the reinforcer. Each rat was placed in the same chamber throughout the experiment. In a first training phase (one session), rats from each group were placed in the chamber for 15 min with the house-light off and the panel of the magazine in open position. During the training phase, for the 'SA pellets' and the 'Yoked pellets' groups, the magazine was filled with 15 food pellets to familiarize rats to eat the reinforcer from the magazine, but it remained empty for the 'Yoked control' rats. In a second training phase, rats received two food magazine training sessions $(20 \mathrm{~min} / \mathrm{session}, 1$ session/day), in which 20 food pellets were delivered according to a variable time schedule (mean $=60 \mathrm{~s}$ ) for the 'SA pellets' and the 'Yoked pellets' groups. No pellet was delivered to animals of the 'Yoked control' group. The house-light of the operant chamber was turned off during this phase. On the first session, the panel of the magazine was blocked in an upward position in order to maintain the food magazine open. For the second session, as for the sessions of the food pellets operant selfadministration procedure, rats had to push away the panel in front of the food magazine to retrieve the food pellet.

Briefly, as for the cocaine operant self-administration experiment, 'SA pellets' rats were first submitted to a FR1 schedule of reinforcement during daily $2 \mathrm{~h}$ sessions for 4 days and to a FR5 schedule during daily $2 \mathrm{~h}$ sessions for 6 days. When the required number of NPs into the active hole was reached, a food pellet was delivered into the magazine. NPs into the inactive hole had no programmed consequence. No cutoff was applied concerning the number of food pellets delivered the rat was able to induce during each session. Two yoked groups were included and exposed to the same associated cues based on the 'SA pellets' group. Each rat from these groups was paired with a rat from the 'SA pellets' group. Rats from the 'Yoked pellets' group received passively the same amount of food pellets as that of 'SA pellets' paired rats, whereas no food pellet was delivered to rats from the 'Yoked control' group. 


\section{Reverse Transcription-quantitative PCR analysis}

Animals were sacrificed $24 \mathrm{~h}$ after the beginning of the last session of cocaine selfadministration or food pellet self-delivery and brain structures of interest were dissected, as described in supplementary Fig. S1. RNA was extracted from rat PFCx and CPu and first strand cDNA was generated from $0.5 \mu \mathrm{g}$ of total RNA using random primers and Reverse Transcriptase (MLV) and the reaction product was used for real time PCR performed with Hot Pol EvaGreen (Euromedex, Souffelweyersheim, France) with a Light Cycler instrument and technology (Roche Applied Science, Indianapolis, IN) and CFX Connect Real Time PCR detection System (Bio-Rad), as previously described [18]. Primers were from Sigma-Aldrich (Saint Louis, MO) and are listed in Table 1. Results were normalized to 36B4 (RPLPO) used as an internal control for gene expression and to $U 6$ snRNA for miR-212/132. Cycling conditions were: $95^{\circ} \mathrm{C}$ for $14 \mathrm{~min}$, then 55 cycles of $95^{\circ} \mathrm{C}$ for $14 \mathrm{~s}, 60^{\circ} \mathrm{C}$ for $18 \mathrm{~s}$ and $72^{\circ} \mathrm{C}$ for $18 \mathrm{~s}$. PCR products were verified by melting curve analysis and their sizes were confirmed by $2 \%$ agarose gel electrophoresis. Real time PCR was conducted three times for each gene/miR of interest, using duplicate samples. Primers were designed with Primer 3 sofware (http://frodo.wi.mit.edu/primer3/input.htm).

\section{Immunohistochemistry}

Twenty-four hours after the beginning of the last session of self-administration or selfdelivery, rats were sacrificed by an overdose of pentobarbital $(100 \mathrm{mg} / \mathrm{kg}$, i.p. $)$ and perfused transcardially with $100 \mathrm{ml}$ saline followed by $1 \%$ paraformaldehyde in phosphate-buffered saline. The brain were post-fixed in $1 \%$ paraformaldehyde in PBS for $1 \mathrm{~h}$ and kept overnight at $4{ }^{\circ} \mathrm{C}$ in $15 \%$ sucrose, then frozen in isopentane at $-40^{\circ} \mathrm{C}$, and finally stored at $-80^{\circ} \mathrm{C}$. Coronal tissue sections (16 $\mu \mathrm{m}$ thick) were prepared using a Microm HM560 S_18 Cryostat. Immunohistochemistry was carried out essentially as described previously [13,37]. Antibody incubation was performed overnight with a polyclonal goat primary Orexin-A specific antibody (C-19, sc-8070, 1:5000). Images of each region of interest were obtained using a microscope (Olympus: Vanox AHBT3; x 20 objective) equipped with a digital camera. For each experimental condition, the number of orexin immunoreactive cells in the hypothalamus was determined using the Image $\mathbf{J}$ software (N.I.H.). The number of immunoreactive cells was counted bilaterally on four consecutive sections per rat, before being averaged to generate the final mean value. Each counting was performed twice by an investigator blinded to the identity of the samples.

\section{Genomic DNA methylation analysis of the PFCx}

High molecular weight DNA was extracted, as previously described [38]. Whole genome methylation analysis was performed on PFCx samples from rats killed $24 \mathrm{~h}$ after the last session of FR5 schedule of reinforcement. The comparison was carried out between cocaine self-administering rats with control rats (Yoked $\mathrm{NaCl}$ ). Briefly, genome-wide $5 \mathrm{mC}$ were quantified by Active Motif (Carlsbad, CA, USA) and purification was achieved through the formation of binding complexes between methylated DNA and the methyl-binding proteins MBD2b and MBD3L1, as previously reported [20].

\section{Statistical analysis}

In behavioral experiments, the preference for the active $v s$ inactive hole was evaluated by comparing the percentage of NPs performed into the active hole $(\% \mathrm{NPa})$ to $50 \%$ considered as random. Daily performance and the mean performance realized during the FR1 period and the FR5 period were compared to 50\%. The acquisition of the task was evaluated by comparing the $\% \mathrm{NPa}$ to $80 \%$, which was considered as the acquisition criterion. Daily 
performance and the mean performance realized during both FR1 (mean (FR1)) and FR5 periods (mean (FR5)) were compared to 80\%, as previously described [37]. The number of NPs into the active (NPa) and the inactive hole (NPi) was evaluated with two-way ANOVA ('active/inactive' and 'FR1/FR5'). The number of rewards self-delivered was assessed by one-way ANOVA with repeated measures in order to evaluate 'Day' effect, as previously described [37]. In RT-qPCR and immunohistochemistry analyses, one-way ANOVA was performed to evaluate 'Group' effect. Neuwman-Keuls post-hoc was performed, if required. Significance was set at $\mathrm{p} \leq 0.05$. Data are expressed as means \pm S.E.M.

\section{Results}

\section{Operant conditioning in cocaine and food pellets self-administering rats}

Cocaine and food self-administering rats were submitted to a FR1 schedule of reinforcement for 4 consecutive days, and then to a FR5 schedule for 6 days during 2-h daily sessions (Fig. 1A). During both schedules, rats self-administered about 100 cocaine injections and selfdelivered about 150 food pellets per day, as described during the FR5 schedule (Fig. 1B). This performance reveals a rapid preference for the active hole, since the percentage of nose pokes in the active hole ( $\mathrm{NPa}$ ) was above $80 \%$ (Fig. 1C) for each reinforcer. In contrast, all yoked control groups displayed no preference for the active or the inactive hole in none of the sessions with a percentage of NPa of about $50 \%$ (data not shown). Only self-administering rats differentiate the hole associated with cocaine or food pellets delivery from the inactive hole and therefore fulfill behavioral acquisition rules, as previously described [37,20]. However, despite food restriction during the operant conditioning for food-self delivery, rats self-administering cocaine made 2.5 more NPa during the time-out period associated with a stimulus light than those self-delivering food pellets (data not shown), consistent with our previous report [37]. These excessive $\mathrm{NPa}$ in drug seeking may result from cocaine-induced impulsive behavior, locomotor hyperactivity and/or stereotypies, but could also represent deficits in behavioral adaptations, since cocaine decreases behavioral flexibility $[39,40]$.

\section{Cocaine and food induce opposite effect on Dnmt3a expression in the PFCx and the CPu}

Cocaine-induced DNA methylation changes are mainly mediated by de novo Dnmt $3 a$ and $3 b$, as previously described by their biphasic time-course regulation following chronic passive treatment or by using a self-administration paradigm [15-17]. Their expression was compared in response to cocaine and food in self-administering rats exposed to the same schedule of reinforcement. In the PFCx reward brain structure, voluntary cocaine intake induced a 1.6fold increase in Dnmt3a upon voluntary intake, whereas a 2-fold decrease was found upon passive and voluntary food intake, the latter compensating the food restriction effect (Fig. 2A). This opposite effect between cocaine and food was also observed in the $\mathrm{CPu}$, but the other way around (Fig. 2B). Indeed, while Dnmt3a was repressed by cocaine, it was induced by food in the $\mathrm{CPu}$. In contrast to the PFCx, this latter activation was actually exacerbating the positive effect of food restriction observed in both brain structures.

In the PFCx, a repression of Dnmt $3 b$ was found simultaneously in response to passive and voluntary cocaine and food intake, suggesting less de novo methylation triggered by Dnmt $3 b$ whose expression was not affected by food restriction (Fig. 2C). In the CPu, Dnmt3b was surprisingly only activated by passive cocaine intake. No change was observed upon passive or voluntary food delivery, despite a significant induction resulting from food restriction (Fig. 2D). These data highlight opposite effects of the two rewarding stimuli on Dnmt $3 a$ in the PFCx and the $\mathrm{CPu}$, effects that do not always require learning and memory processes associated with operant conditioning. They also indicate that de novo DNA 
methylation patterns mediated by Dnmt3a are different between cocaine and food and from one brain structure to another. On the other hand, the selective repression of Dnmt $3 b$ in the PFCx suggests less DNA methylation of its target sequences in response to both reinforcers independently of the mode of administration.

\section{Tet genes are widely repressed by cocaine and food}

The ten eleven translocation (Tet) family of enzymes oxidizes 5-methylcytosine $(5 \mathrm{mC})$ and promotes locus-specific reversal of DNA methylation. Three Tet proteins catalyze the successive oxidation of $5 \mathrm{mC}$ to 5 -hydroxymethylcytosine $(5 \mathrm{hmC}), 5$-formylcytosine (5fC), and 5-carboxylcytosine $(5 \mathrm{caC})$. The oxidation products are intermediates in the conversion of $5 \mathrm{mC}$ to unmodified cytosine, providing the first steps for active DNA demethylation and implying that DNA methylation patterns are not as static as previously assumed $[41,42]$.

In the PFCx, independently of the mode of administration, all Tet genes were found to be repressed by cocaine relative to saline treatment (Fig. 3ABC). The effect of food was more heterogeneous, since only Tet 3 was repressed by both passive and voluntary delivery (Fig. 3C). In contrast to cocaine, food did not affect Tet1 mRNA levels (Fig. 3A) and Tet2 was intriguingly selectively induced by passive food delivery without any change in selfadministering rats relative to yoked control rats (Fig. 3B). No significant change in Tet gene expression was detected upon food restriction. Thus, Tet1 and Tet 2 are not similarly regulated by cocaine and food (Fig. $3 \mathrm{AB}$ ), whereas Tet 3 is repressed by both reinforcers in the PFCx in which the reward and its associated cues are sufficient without requiring learning and memory processes (Fig. 3C). In the $\mathrm{CPu}$, the three Tet genes were repressed by both rewarding stimuli to a similar extent by passive and voluntary intake (Fig. 3DEF). However, Tet 2 repression by food should be taken with caution, as it compensates the stimulatory effect of food restriction that was of the same range (Fig. 3E).

Taken together, our data underline a repression of Tet genes in most experimental conditions, indicating that less $5 \mathrm{mC}$ oxidation products are generated by both a drug of abuse and a natural reinforcer. The repression would ultimately prevent DNA demethylation following the involvement of the thymine DNA glycosylase-mediated base excision DNA repair pathway involved in the final step of demethylation [43].

\section{Selective repression of $\mathrm{miR}-212$ and $\mathbf{- 1 3 2}$ by (passive and voluntary) cocaine and food intake in the dorsal striatum}

miR-212 and -132 belong to an intronic polycistronic cluster activated by CREB and modulate dendritic plasticity by controlling MeCP 2 expression, as a validated target playing a critical role in cocaine intake [44,45]. Indeed, increased MeCP2 expression by cocaine in the dorsal striatum inhibits miR-212 expression that, in turn represses MeCP2 expression and their homeostatic interactions have been suggested to be important in regulating vulnerability to cocaine addiction $[14,46]$. In addition, an up regulation of microRNA-212 in the dorsal striatum of rats exposed to cocaine decreased operant responding during the post-infusion time-out period, thereby identifying its role in regulating compulsive-like cocaine intake [47]. We compared the expression of the primary miR-212/132 transcript (pri-miR-212/132) with that of each miRNA in brain structures of rats exposed to passive or voluntary cocaine and food intake. The gene cluster structure and sequence with the relative position of the primers used are depicted in supplementary Fig. S2. When examining the PFCx, overall, cocaine did not affect their levels relative to control saline-treated rats, except a slight increase observed for miR-212 in voluntary relative to passive administration (Fig. 4ABC). Similarly, miR-212 and -132 levels were not altered by food delivery, despite a significant increase of their primary transcript in response to passive food pellet delivery. This increase was of the same range as that of its decrease resulting from food restriction (Fig. 4A), showing that 
intriguingly only passive food delivery compensates the food restriction effect. Indeed, since food restriction was used to motivate rats in operant-conditioning experiments, its effect was addressed by comparing yoked control rats from food pellet experiments under food restriction with yoked control rats from cocaine experiments that were not. Food restriction decreased pri-miR-212/132 expression, as that of miR-212 and miR-132 (Fig. 4ABC), suggesting that a transcriptional repression mediates the effect of food deprivation by altering the regulation of their target genes in the PFCx. However, their role in triggering the effect of cocaine and food intake is not likely in this brain structure.

We next examined the $\mathrm{CPu}$ (Fig. 4DEF) that serves as a key brain area for habits, reward association learning and compulsive drug-seeking behaviors [48,49]. The pri-miR212/132 levels were not altered neither by passive and voluntary cocaine and food intake, nor by food restriction (Fig. 4D), unlike in the PFCx, suggesting a lack of transcriptional effect. However, both miRs were strongly repressed following contingent and not contingent cocaine administration (Fig. 4EF), consistent with increased Mecp2 expression previously reported in various experimental models [50,23] and with its inhibitory effect on mature miR-212 expression [45]. A repression was also observed in response to food pellet delivery $24 \mathrm{~h}$ after the beginning of the last session and intriguingly, providing limited amount of food, independently of the administration mode further emphasizing the food restriction effect. Nevertheless, the repression of both miRs observed in cocaine groups was of a higher magnitude than that in food pellets groups, as for the NPas during the time-out period, supporting the role of miR-212 in compulsive behavior for drug-seeking [47]. The data underline a specific repression of both miRs by cocaine and food reward with their associated cues in the $\mathrm{CPu}$, a repression that does not require learning and memory processes involved in operant conditioning.

\section{Orexin receptor-1 gene methylation and expression in $\mathrm{PFCx}$}

Among orexin receptors, Orx R1 plays an important role in regulating the reinforcing and reward-enhancing properties of cocaine, as well as in the neurobiological effects driving various drugs of abuse [29] [51] [30] [31] [52] [33]. Having previously performed a genomewide DNA methylation study in the PFCx of rats after cocaine intake [20], we know the methylation status of the genes examined here. The most prominent difference in gene methylation was found for Orx R1. Indeed, hypomethylated regions were identified in the gene promoter, within gene body and downstream of the gene with a ratio of $5 \mathrm{mC}$ (cocaine]/[saline] ranging from 0.5 to 0.9 (Fig. 5A). When next analyzing its expression in the PFCx (Fig. 5B), passive and voluntary cocaine intake was found to induce Orx Rlgene expression. In contrast, no difference was observed in Orx $R 1 \mathrm{mRNA}$ levels neither upon food pellets intake, nor upon food restriction. In the $\mathrm{CPu}$, only food restriction was affecting its levels with a 4-fold increase (Fig. 5C), whereas passive and voluntary food intake remained without significant effect. Thus, an inverse correlation was found in the PFCx between gene methylation and transcription, which is consistent with the silencing role of methylation in upstream gene DNA sequences. Orx $R I$ is therefore a cocaine target gene regulated at least in part by DNA methylation in the PFCx without alteration of its expression by food selfdelivery.

\section{Cocaine and food induced different regulation of prepro-orexin mRNA and protein- polypeptide in the hypothalamus}

Orexin-A and B belong to the same prepro-orexin gene which is transcribed and translated before secretion and cleavage producing each single peptide. Its transcription exclusively occurs in the lateral hypothalamus (LH) in orexinergic neurons that widely project throughout 
the brain including key structures of the limbic system which are "multi-tasking" neurons regulating functions like arousal, sleep/wake states, feeding behavior, energy homeostasis, anxiety and addictive behaviors [26-28].

We examined expression of the prepro-orexin peptide by immunohistochemistry (Fig. 6ABC) and gene expression by RT-qPCR (Fig. 6D) in the lateral hypothalamus $24 \mathrm{~h}$ after the last session of cocaine and food pellet administration. Passive administration of cocaine and food did not alter the number or the intensity of immunoreactive neurons, nor orexin gene expression, since no differences were detected between 'yoked control' rats and rats receiving cocaine or food passively. However, voluntary administration of cocaine and food triggered striking different responses. Indeed, cocaine self-administration resulted in a significant increase in the number of orexin immunoreactive cells (Fig. 6AC) and was found to slightly increase prepro-orexin gene expression without reaching statistical significance relative to the two other controls (Fig. 6D). This increase appears consistent with the role of orexin in the control of arousal $[28,53]$. In contrast, food self-delivery resulted in a significant decrease of the number of orexin positive cells (Fig. 6BC) and in gene expression (Fig. 6D), compared with the two other control groups. The repression, solely observed following contingent food pellet delivery, appeared to compensate for the induction of peptide and gene expression that result from the food restriction effect (Fig. 6CD). Thus, orexin induction by cocaine selfadministration and repression by food restriction underline a marked divergence between the two reinforcers.

\section{Evidence for an orexin mRNA transport to the $\mathrm{CPu}$ controlled by cocaine and food}

Although orexins are known to be exclusively transcribed in neurons within the lateral hypothalamus (Peyron C et al. $1998 \mathrm{~J}$ Neurosc.), we nevertheless checked their mRNA levels in the $\mathrm{CPu}$ and PFCx. Surprisingly, or $x$ mRNA was detected in the $\mathrm{CPu}$, but not in the PFCx (Fig. 7A). Considering that orexin-expressing neurons project over virtually the entire brain and spinal cord, this result reveals an unexpected mRNA transport from the hypothalamus to the $\mathrm{CPu}$. No significant changes were detected in the $\mathrm{CPu}$ upon cocaine administration (Fig. 7B). Nevertheless, orx mRNA levels were significantly downregulated by passive and voluntary food intake (Fig. 7C), as well as by food restriction (Fig. 7D). This modulation appears consistent with that observed in food SA-rats in the LH in food restricted rats (Fig. 6), underlining a correlation between orx mRNA levels in the $\mathrm{CPu}$ and those observed in the hypothalamus where they are synthesized. 


\section{Discussion}

In the present study we have demonstrated that at the molecular level neural circuits activated by drugs of abuse and natural reinforcers do only partially overlap, thus further supporting results from electrophysiological and fMRI studies previously suggested. This is illustrated by stricking changes in the expression of genes controling DNA methylation/demethylation processes and in orexins and orx-R1 involved in the control of satiety or appetite signals. These behavior-dependent changes were observed in response to both reinforcers, but differed depending on passive or voluntary intake, feeding conditions and from one brain structure to another.

When comparing Dnmt3 expression in response to cocaine and food under the same schedule of reinforcement, the most prominent difference was observed for Dnmt3a. Opposite responses to cocaine and food passive and voluntary intakes were observed in both brain structures, despite a stimulatory effect of food restriction (Fig. 3AB). In addition, our data highlight its tissue-specific regulation, since Dnmt $3 a$ was repressed and activated in response to each rewarding agent. In contrast, Dnmt3b levels were similarly repressed by both reinforcers in the PFCx independently of the administration mode (Fig. 3C), while voluntary intake of both did not lead to significant changes in the $\mathrm{CPu}$, a key brain structure altered in cocaine addicted humans involved in reward association learning [48,49]. Taken together with other available data, our results demonstrate that Dnmt3a represents the major Dnmt differentially regulated by cocaine and food. Overall DNA methylation patterns triggered by a drug of abuse and a natural reinforcer differ within brain structures. Identification of its targets sequences may certainly shed light into the mechanism by which DNA methylation contributes to addictive behaviors. Among Dnmts, Dnmt1 is essential for maintaining DNA methylation patterns and Dnmt3a and $\mathrm{b}$ are required for de novo methylation [54], it is noteworthy that these enzymes have overlapping and different target genes and functions [55] [56]. Moreover, a pharmacological agent like cocaine induces DNA methylation and gene repression by a Mecp2-mediated mechanism that was initially reported for the $C d k l 5$ [18] and the PPIc [15] genes. In the mean time, the effect of inhibition of DNA methylation in druginduced learning and memory was also described [57]. Consistent with these studies, de novo Dnmt3a and b enzymes were found to be modulated by repeated cocaine exposure with a daily biphasic expression [15-17]. Cocaine-induced brain DNA methylation changes were thereafter documented for several genes and by genome wide studies, suggesting that these dynamic changes are important in cocaine-induced behavior [50,23,11]. Interestingly a relationship between feeding behavior or obesity and DNA methylation has been documented as well: i) Mecp2 deletion in the hypothalamus alters social and feeding behavior [58]; ii) Mecp2 mutation disrupts body weight balance in Rett patients [59], while in mutant mice, it alters leptin-signaling components regulating Pomc and Agrp expression which are essential signals for satiety and appetite [60]; iii) high fat or methyl donor supplementation in early life alters DNA methylation in the brain [61]; iv) maternal methyl donor-deficient diet causes a reduction of the body weight and length of embryos during the gestational period [62] and reduces global brain DNA methylation [63]. These studies support the concept that DNA methylation provides a strong mechanistic link between environment, nutrition and diseases including addictive behaviors [64]. In addition, the link between DNA methylation and food reward was illustrated by studies having demonstrated that i) human males with hypomorphic mutations overexpressing the MeCP2 or females with milder variants of Rett syndrome often become obese, as in some Mecp2 mutant mice [58] and ii) Mecp2 expression was increased in the $\mathrm{CPu}$ upon food restriction [37]. 
Similarly to Dnmts, Tet proteins may also display tissue-specific biological functions and recognize common and specific 5mC target sequences [65,42]. Since all of them are repressed by cocaine and food in the $\mathrm{CPu}$, less $5 \mathrm{mC}$ oxidation products should be generated in this brain structure. Hence, less cytosine demethylation in response to both reinforcers is expected. Changes in the relative levels of intermediate oxidation products $(5 \mathrm{hmC}, 5 \mathrm{fC}, 5 \mathrm{caC})$ may lead to altered gene expression. In the PFCx, all Tet genes were repressed by cocaine, as in the $\mathrm{CPu}$ (Fig. 4ABC). Interestingly, 3 DMRs were identified within the Tetl gene in the $\mathrm{PFCx}$ and all were hypermethylated with a ratio of $5 \mathrm{mC}$ (cocaine/saline) ranging from 1.3 to 2.7 (supplementary table), indicating that as in promoter sequences, $5 \mathrm{mC}$ located within the gene correlates with repression by cocaine. In contrast, food only repressed Tet 3 without altering Tetl and Tet 2 mRNA levels under contingent delivery, suggesting no change in the oxidation of $5 \mathrm{mC}$ triggered by the two family members (Fig. 4ABC). The data are again consistent with non overlapping neural circuits activated by a drug of abuse and a natural reinforcer and underline brain structure specific regulations of Tet genes.

The regulation of de novo Dnmta and Tet genes by cocaine and food appears quite complex, the food data being sometimes biased by food restriction that is required to train rats in food self-delivery experiments [37]. Considering this limitation, data interpretation for food delivery must be taken with caution. Nevertheless, genome wide methylation patterns in response to cocaine in the whole brain, the PFCx, or the NAc have been reported. No or little changes have been detected in global DNA methylation $[8,19,66,9,67,20]$, the pattern of which being not random, but tightly regulated in a tissue-specific manner [68]. Hence, striking changes in the expression of major factors controlling this process, including Dnmts with specific target sequences [55,56], strongly suggest that cocaine and food-induced-DNA methylation modifications differ, but mainly affect the distribution of modified cytosines, rather than their whole amount throughout the brain genome. Our genome wide data in the PFCx further support the idea that DMRs and genes harbor differences in $5 \mathrm{mC}$, although global changes in $5 \mathrm{mC}$ do not significantly differ between cocaine self-administering rat and their controls counterparts.

Previous findings have shown that in the dorsal striatum, Mecp2 acts as a proaddiction transcriptional repressor that, by attenuating miR-212 expression in response to cocaine increases vulnerability to addiction [45]. miR-212 was also proposed to play an important role in regulating compulsive-like cocaine intake [47], a proposal that is further supported by its stronger repression by cocaine than by food administration associated with more NPas during the time-out period. We show here that miR-132 is also repressed by cocaine and food in the $\mathrm{CPu}$, independently of the administration mode. This is consistent with the hypothesis that neural circuits activated by drugs of abuse and natural reinforcers overlapp in the $\mathrm{CPu}$. Moreover, both miRs belong to the same polycistronic cluster located in a CpG enriched region with conserved regulatory elements activated by CREB (Fig. S2), the activity of which affects drug rewards as well as preference for natural reinforcers [69]. Hence, their common transcriptional regulation may appear likely. Indeed, their conserved upstream region could be methylated and recognized by cocaine-induced Mecp2 [50,23]. In addition, Mecp2 could act as a transcriptional repressor in agreement with its negative homeostatic relationship with both miRs [70-72]. Finally, knock down of Mecp2 increases mature miR-212 and miR-132 expression in cultured cells [73] underlining its role as a transcriptional repressor. However, despite a striking inhibition of both pre-miRs expression in response to cocaine and food, no change was observed in the primary miR-212/132 transcript levels (Fig. 2D). Although this repression is consistent with a positive correlation between mature and pre-miR expression [74,75], a transcriptional regulation of the pri-miR is not likely. MiRs are also regulated at the level of processing in which pri-miRs are cleaved by the Microprocessor complex including DGCR8 and Drosha into pre-miRNA and exported 
from the nucleus to the cytoplasm. Interestingly, inconsistencies between levels of pri-miR and of their derived precursor and mature forms have been reported to be more obvious for so-called polycistronic or miR clusters, indicating a miR specific regulation [76]. Hence, we propose that Mecp2 mediates cocaine and food effects by modulating the processing of the polycistronic pri-miR-212/132 cluster into pre- and mature forms, in agreement with studies having reported that Mecp2 regulates RNA splicing [77] and suppresses nuclear pri-miR processing by regulating the DGCR8/Drosha complex [78].

Interestingly, the Orx $R l$ gene was found to be hypomethylated within six DMRs identified in the gene promoter, within the gene or downstream in the PFCx of cocaine selfadministering rats, indicating DNA methylation changes, as previously reported for Orx and orx $R 2$ genes [79-81]. Gene hypomethylation was associated with its overexpression. The overexpression is likely to contribute to addictive-like behavior, since orexin receptor antagonists attenuate motivational and hedonic properties of cocaine [34]. By looking at the role of orexins that are involved in feeding and addictive behaviors, their expression was found to be induced in cocaine self-administering rats and repressed in food pellet selfdelivering rats. The repression observed following voluntary food intake was actually only compensating the known food restriction effect to reach levels that are similar as those observed in control rats having ad libitum access to food. Nevertheless, despite this compensation, the activation in response to cocaine highlights a marked divergence between the two reinforcer effects. That orexin levels were not affected by passive cocaine and food intake indicates the requirement of learning and memory processes involved in operant conditioning.

The presence of orx mRNA in the $\mathrm{CPu}$ is surprising and suggests an axonal transport from LH neurons cell bodies to distal sites containing the translation machinery [82]. Its level is much lower than in the hypothalamus (Fig. 7A) which appears consistent with a low density of orexin-containing fibers reported in the anterior $\mathrm{CPu}$ by immunohistochemistry [83]. Since both orexin A and B peptides are present in the $\mathrm{CPu}$, they may result from peptide transport and/or local translation of mRNA transcribed in the hypothalamus. On one hand, the transport of mRNA encoding orx A and B prior to a local translation may require less energy, compared with transport of both peptides. It may represent an additional control of orx peptide levels at sites distal from their transcription site. Whether orx mRNA that was not detected in the PFCx, is present in other brain structures expressing both receptors remains to be determined. On the other hand, thorough in situ hybridization analyses of orexin receptors in the whole brain have shown that the non selective Orx R2 was not detected in the PFCx [84], although present in various layers of the neocortex, in the piriform cortex or in the bed nucleus of stria terminalis [27]. Hence, axonal transport of both the polypeptide and its mRNA to the PFCx may not be required.

In summary, the present data demonstrate that DNA methylation factors and the orexinergic system are not similarly regulated by a drug of abuse and a natural reinforcer, providing new insight into the mechanism by which each factor triggers reward. They well support at the molecular level the concept that neural circuits activated by either of them only partially overlap, a conclusion previously reported based on electrophysiological and functional magnetic resonance imaging studies. De novo gene DNA methylation changes including various $5 \mathrm{mC}$ oxidative products resulting from each stimulus are therefore likely to be different in the brain. Whether and how each of these products contributes to long lasting behaviors requires further investigation. Elucidation of the molecular mechanisms dissociating these reinforcers is required prior to conceive novel diagnostic and therapeutic tools for addictive disorders. 


\section{References}

1. Carelli RM, Ijames SG, Crumling AJ (2000) Evidence that separate neural circuits in the nucleus accumbens encode cocaine versus "natural" (water and food) reward. The Journal of neuroscience : the official journal of the Society for Neuroscience 20 (11):4255-4266

2. Levy D, Shabat-Simon M, Shalev U, Barnea-Ygael N, Cooper A, Zangen A (2007) Repeated electrical stimulation of reward-related brain regions affects cocaine but not "natural" reinforcement. The Journal of neuroscience : the official journal of the Society for Neuroscience 27 (51):14179-14189

3. Cameron CM, Carelli RM (2012) Cocaine abstinence alters nucleus accumbens firing dynamics during goal-directed behaviors for cocaine and sucrose. Eur J Neurosci 35 (6):940951

4. Cameron CM, Wightman RM, Carelli RM (2014) Dynamics of rapid dopamine release in the nucleus accumbens during goal-directed behaviors for cocaine versus natural rewards. Neuropharmacology 86:319-328. doi:10.1016/j.neuropharm.2014.08.006

5. Lu H, Chefer S, Kurup PK, Guillem K, Vaupel DB, Ross TJ, Moore A, Yang Y, Peoples LL, Stein EA (2012) fMRI response in the medial prefrontal cortex predicts cocaine but not sucrose self-administration history. Neuroimage 62 (3):1857-1866

6. DiLeone RJ, Taylor JR, Picciotto MR (2012) The drive to eat: comparisons and distinctions between mechanisms of food reward and drug addiction. Nat Neurosci 15 (10):1330-1335

7. Romieu P, Host L, Gobaille S, Sandner G, Aunis D, Zwiller J (2008) Histone deacetylase inhibitors decrease cocaine but not sucrose self-administration in rats. The Journal of neuroscience : the official journal of the Society for Neuroscience 28 (38):9342-9348

8. Tian W, Zhao M, Li M, Song T, Zhang M, Quan L, Li S, Sun ZS (2012) Reversal of cocaine-conditioned place preference through methyl supplementation in mice: altering global DNA methylation in the prefrontal cortex. PLoS One 7 (3):e33435

9. Wright KN, Hollis F, Duclot F, Dossat AM, Strong CE, Francis TC, Mercer R, Feng J, Dietz DM, Lobo MK, Nestler EJ, Kabbaj M (2015) Methyl supplementation attenuates cocaine-seeking behaviors and cocaine-induced c-Fos activation in a DNA methylationdependent manner. The Journal of neuroscience : the official journal of the Society for Neuroscience 35 (23):8948-8958

10. Cadet JL, Bisagno V, Milroy CM (2014) Neuropathology of substance use disorders. Acta Neuropathol 127 (1):91-107

11. Anglard P, Zwiller J (2017) Cocaine and epigenetics: an overview. Book chapter in the Neuroscience of cocaine: mechanisms and treatment Elsevier Inc. Academic Press:79-88

12. de Sa Nogueira D, Merienne K, Befort K (2018) Neuroepigenetics and addictive behaviors: where do we stand? Neurosci Biobehav Rev

13. Cassel S, Carouge D, Gensburger C, Anglard P, Burgun C, Dietrich JB, Aunis D, Zwiller $\mathrm{J}$ (2006) Fluoxetine and cocaine induce the epigenetic factors MeCP2 and MBD1 in adult rat brain. Mol Pharmacol 70 (2):487-492

14. Im HI, Hollander JA, Bali P, Kenny PJ (2010) MeCP2 controls BDNF expression and cocaine intake through homeostatic interactions with microRNA-212. Nat Neurosci 13 (9):1120-1127

15. Anier K, Malinovskaja K, Aonurm-Helm A, Zharkovsky A, Kalda A (2010) DNA methylation regulates cocaine-induced behavioral sensitization in mice. Neuropsychopharmacology 35 (12):2450-2461

16. LaPlant Q, Vialou V, Covington HE, 3rd, Dumitriu D, Feng J, Warren BL, Maze I, Dietz DM, Watts EL, Iniguez SD, Koo JW, Mouzon E, Renthal W, Hollis F, Wang H, Noonan MA, Ren Y, Eisch AJ, Bolanos CA, Kabbaj M, Xiao G, Neve RL, Hurd YL, Oosting RS, Fan G, 
Morrison JH, Nestler EJ (2010) Dnmt3a regulates emotional behavior and spine plasticity in the nucleus accumbens. Nat Neurosci 13 (9):1137-1143

17. Pol Bodetto S, Carouge D, Fonteneau M, Dietrich JB, Zwiller J, Anglard P (2013) Cocaine represses protein phosphatase-1Cbeta through DNA methylation and Methyl-CpG Binding Protein-2 recruitment in adult rat brain. Neuropharmacology 73:31-40

18. Carouge D, Host L, Aunis D, Zwiller J, Anglard P (2010) CDKL5 is a brain MeCP2 target gene regulated by DNA methylation. Neurobiol Dis 38 (3):414-424

19. Fragou D, Zanos P, Kouidou S, Njau S, Kitchen I, Bailey A, Kovatsi L (2013) Effect of chronic heroin and cocaine administration on global DNA methylation in brain and liver. Toxicol Lett 218 (3):260-265

20. Fonteneau M, Filliol D, Anglard P, Befort K, Romieu P, Zwiller J (2017) Inhibition of DNA methyltransferases regulates cocaine self-administration by rats: a genome-wide DNA methylation study. Genes Brain Behav 16 (3):313-327

21. Baker-Andresen D, Zhao Q, Li X, Jupp B, Chesworth R, Lawrence AJ, Bredy T (2015) Persistent variations in neuronal DNA methylation following cocaine self-administration and protracted abstinence in mice. Neuroepigenetics 4:1-11

22. Ausio J (2016) MeCP2 and the enigmatic organization of brain chromatin. Implications for depression and cocaine addiction. Clin Epigenetics 8:58

23. Vaillancourt K, Ernst C, Mash D, Turecki G (2017) DNA Methylation Dynamics and Cocaine in the Brain: Progress and Prospects. Genes (Basel) 8 (5):1-19

24. Panlilio LV, Goldberg SR (2007) Self-administration of drugs in animals and humans as a model and an investigative tool. Addiction 102 (12):1863-1870

25. Remenyi J, Hunter CJ, Cole C, Ando H, Impey S, Monk CE, Martin KJ, Barton GJ, Hutvagner G, Arthur JS (2010) Regulation of the miR-212/132 locus by MSK1 and CREB in response to neurotrophins. Biochem J 428 (2):281-291

26. Sakurai T, Amemiya A, Ishii M, Matsuzaki I, Chemelli RM, Tanaka H, Williams SC, Richardson JA, Kozlowski GP, Wilson S, Arch JR, Buckingham RE, Haynes AC, Carr SA, Annan RS, McNulty DE, Liu WS, Terrett JA, Elshourbagy NA, Bergsma DJ, Yanagisawa M (1998) Orexins and orexin receptors: a family of hypothalamic neuropeptides and G proteincoupled receptors that regulate feeding behavior. Cell 92 (4):573-585

27. Zhang GC, Mao LM, Liu XY, Wang JQ (2007) Long-lasting up-regulation of orexin receptor type 2 protein levels in the rat nucleus accumbens after chronic cocaine administration. J Neurochem 103 (1):400-407

28. Calipari ES, Espana RA (2012) Hypocretin/orexin regulation of dopamine signaling: implications for reward and reinforcement mechanisms. Front Behav Neurosci 6:54

29. Espana RA, Oleson EB, Locke JL, Brookshire BR, Roberts DC, Jones SR (2010) The hypocretin-orexin system regulates cocaine self-administration via actions on the mesolimbic dopamine system. Eur J Neurosci 31 (2):336-348

30. Hollander JA, Pham D, Fowler CD, Kenny PJ (2012) Hypocretin-1 receptors regulate the reinforcing and reward-enhancing effects of cocaine: pharmacological and behavioral genetics evidence. Front Behav Neurosci 6:47

31. Zhou L, Ghee SM, Chan C, Lin L, Cameron MD, Kenny PJ, See RE (2012) Orexin-1 receptor mediation of cocaine seeking in male and female rats. J Pharmacol Exp Ther 340 (3):801-809

32. Boutrel B, Steiner N, Halfon O (2013) The hypocretins and the reward function: what have we learned so far? Front Behav Neurosci 7:59

33. Levy KA, Brodnik ZD, Shaw JK, Perrey DA, Zhang Y, Espana RA (2017) Hypocretin receptor 1 blockade produces bimodal modulation of cocaine-associated mesolimbic dopamine signaling. Psychopharmacology (Berl) 234 (18):2761-2776 
34. Gentile TA, Simmons SJ, Barker DJ, Shaw JK, Espana RA, Muschamp JW (2017) Suvorexant, an orexin/hypocretin receptor antagonist, attenuates motivational and hedonic properties of cocaine. Addiction biology. doi:10.1111/adb.12507

35. James MH, Mahler SV, Moorman DE, Aston-Jones G (2017) A Decade of Orexin/Hypocretin and Addiction: Where Are We Now? Curr Top Behav Neurosci 33:247281

36. Scammell TE, Winrow CJ (2012) Orexin receptors: pharmacology and therapeutic opportunities. Annu Rev Pharmacol Toxicol 51:243-266

37. Pol Bodetto S, Romieu P, Sartori M, Tesone-Coelho C, Majchrzak M, Barbelivien A, Zwiller J, Anglard P (2014) Differential regulation of MeCP2 and PP1 in passive or voluntary administration of cocaine or food. The international journal of neuropsychopharmacology / official scientific journal of the Collegium Internationale Neuropsychopharmacologicum:114. doi:10.1017/S1461145714000972

38. Luo D, Mari B, Stoll I, Anglard P (2002) Alternative splicing and promoter usage generates an intracellular stromelysin 3 isoform directly translated as an active matrix metalloproteinase. J Biol Chem 277 (28):25527-25536

39. Stalnaker TA, Takahashi Y, Roesch MR, Schoenbaum G (2009) Neural substrates of cognitive inflexibility after chronic cocaine exposure. Neuropharmacology 56 Suppl 1:63-72

40. van Holst RJ, Schilt T (2011) Drug-related decrease in neuropsychological functions of abstinent drug users. Curr Drug Abuse Rev 4 (1):42-56

41. Ito S, Shen L, Dai Q, Wu SC, Collins LB, Swenberg JA, He C, Zhang Y (2011) Tet proteins can convert 5-methylcytosine to 5-formylcytosine and 5-carboxylcytosine. Science 333 (6047):1300-1303

42. Rasmussen KD, Helin K (2016) Role of TET enzymes in DNA methylation, development, and cancer. Genes Dev 30 (7):733-750

43. Jin C, Qin T, Barton MC, Jelinek J, Issa JP (2015) Minimal role of base excision repair in TET-induced global DNA demethylation in HEK293T cells. Epigenetics 10 (11):1006-1013

44. Wanet A, Tacheny A, Arnould T, Renard P (2012) miR-212/132 expression and functions: within and beyond the neuronal compartment. Nucleic Acids Res 40 (11):47424753

45. Bali P, Kenny PJ (2013) MicroRNAs and Drug Addiction. Front Genet 4:43

46. Feng J, Nestler EJ (2013) Epigenetic mechanisms of drug addiction. Curr Opin Neurobiol 23 (4):521-528

47. Hollander JA, Im HI, Amelio AL, Kocerha J, Bali P, Lu Q, Willoughby D, Wahlestedt C, Conkright MD, Kenny PJ (2010) Striatal microRNA controls cocaine intake through CREB signalling. Nature 466 (7303):197-202

48. Volkow ND, Wang GJ, Telang F, Fowler JS, Logan J, Childress AR, Jayne M, Ma Y, Wong C (2006) Cocaine cues and dopamine in dorsal striatum: mechanism of craving in cocaine addiction. The Journal of neuroscience : the official journal of the Society for Neuroscience 26 (24):6583-6588

49. Haruno M, Kawato M (2006) Different neural correlates of reward expectation and reward expectation error in the putamen and caudate nucleus during stimulus-action-reward association learning. J Neurophysiol 95 (2):948-959

50. Sadri-Vakili G (2015) Cocaine triggers epigenetic alterations in the corticostriatal circuit. Brain Res 1628 (Pt A):50-59. doi:10.1016/j.brainres.2014.09.069

51. Espana RA (2012) Hypocretin/orexin involvement in reward and reinforcement. Vitam Horm 89:185-208

52. Mahler SV, Moorman DE, Smith RJ, James MH, Aston-Jones G (2014) Motivational activation: a unifying hypothesis of orexin/hypocretin function. Nat Neurosci 17 (10):12981303 
53. Alexandre C, Andermann ML, Scammell TE (2013) Control of arousal by the orexin neurons. Curr Opin Neurobiol 23 (5):752-759

54. Goll MG, Bestor TH (2005) Eukaryotic cytosine methyltransferases. Annu Rev Biochem 74:481-514

55. Challen GA, Sun D, Mayle A, Jeong M, Luo M, Rodriguez B, Mallaney C, Celik H, Yang L, Xia Z, Cullen S, Berg J, Zheng Y, Darlington GJ, Li W, Goodell MA (2014) Dnmt3a and Dnmt3b have overlapping and distinct functions in hematopoietic stem cells. Cell Stem Cell 15 (3):350-364

56. Liao J, Karnik R, Gu H, Ziller MJ, Clement K, Tsankov AM, Akopian V, Gifford CA, Donaghey J, Galonska C, Pop R, Reyon D, Tsai SQ, Mallard W, Joung JK, Rinn JL, Gnirke A, Meissner A (2015) Targeted disruption of DNMT1, DNMT3A and DNMT3B in human embryonic stem cells. Nat Genet 47 (5):469-478

57. Han J, Li Y, Wang D, Wei C, Yang X, Sui N (2010) Effect of 5-aza-2-deoxycytidine microinjecting into hippocampus and prelimbic cortex on acquisition and retrieval of cocaineinduced place preference in C57BL/6 mice. Eur J Pharmacol 642 (1-3):93-98

58. Fyffe SL, Neul JL, Samaco RC, Chao HT, Ben-Shachar S, Moretti P, McGill BE, Goulding EH, Sullivan E, Tecott LH, Zoghbi HY (2008) Deletion of Mecp2 in Sim1expressing neurons reveals a critical role for MeCP2 in feeding behavior, aggression, and the response to stress. Neuron 59 (6):947-958

59. Kleefstra T, Yntema HG, Oudakker AR, Romein T, Sistermans E, Nillessen W, van Bokhoven H, de Vries BB, Hamel BC (2002) De novo MECP2 frameshift mutation in a boy with moderate mental retardation, obesity and gynaecomastia. Clin Genet 61 (5):359-362

60. Torres-Andrade R, Moldenhauer R, Gutierrez-Bertin N, Soto-Covasich J, MancillaMedina C, Ehrenfeld C, Kerr B (2014) The increase in body weight induced by lack of methyl CpG binding protein-2 is associated with altered leptin signalling in the hypothalamus. Exp Physiol 99 (9):1229-1240

61. Plucinska K, Barger SW (2018) Maternal obesity reprograms offspring's executive brain centers in a sex-specific manner?: An Editorial for 'Perinatal high fat diet and early life methyl donor supplementation alter one carbon metabolism and DNA methylation in the brain' on page 362. J Neurochem 145 (5):358-361

62. Kerek R, Geoffroy A, Bison A, Martin N, Akchiche N, Pourie G, Helle D, Gueant JL, Bossenmeyer-Pourie C, Daval JL (2013) Early methyl donor deficiency may induce persistent brain defects by reducing Stat3 signaling targeted by miR-124. Cell Death Dis 4:e755

63. Geoffroy A, Kerek R, Pourie G, Helle D, Gueant JL, Daval JL, Bossenmeyer-Pourie C (2016) Late Maternal Folate Supplementation Rescues from Methyl Donor DeficiencyAssociated Brain Defects by Restoring Let-7 and miR-34 Pathways. Mol Neurobiol 54 (7):5017-5033

64. Cadet JL (2016) Epigenetics of Stress, Addiction, and Resilience: Therapeutic Implications. Mol Neurobiol 53 (1):545-560

65. Tan L, Shi YG (2012) Tet family proteins and 5-hydroxymethylcytosine in development and disease. Development 139 (11):1895-1902

66. Feng J, Shao N, Szulwach KE, Vialou V, Huynh J, Zhong C, Le T, Ferguson D, Cahill ME, Li Y, Koo JW, Ribeiro E, Labonte B, Laitman BM, Estey D, Stockman V, Kennedy P, Courousse T, Mensah I, Turecki G, Faull KF, Ming GL, Song H, Fan G, Casaccia P, Shen L, Jin P, Nestler EJ (2015) Role of Tet1 and 5-hydroxymethylcytosine in cocaine action. Nat Neurosci 18 (4):536-544

67. Massart R, Barnea R, Dikshtein Y, Suderman M, Meir O, Hallett M, Kennedy P, Nestler EJ, Szyf M, Yadid G (2015) Role of DNA methylation in the nucleus accumbens in incubation of cocaine craving. The Journal of neuroscience : the official journal of the Society for Neuroscience 35 (21):8042-8058. doi:10.1523/JNEUROSCI.3053-14.2015 
68. Chen ZX, Riggs AD (2011) DNA methylation and demethylation in mammals. J Biol Chem 286 (21):18347-18353

69. Barrot M, Olivier JD, Perrotti LI, DiLeone RJ, Berton O, Eisch AJ, Impey S, Storm DR, Neve RL, Yin JC, Zachariou V, Nestler EJ (2002) CREB activity in the nucleus accumbens shell controls gating of behavioral responses to emotional stimuli. Proceedings of the National Academy of Sciences of the United States of America 99 (17):11435-11440

70. Klein ME, Lioy DT, Ma L, Impey S, Mandel G, Goodman RH (2007) Homeostatic regulation of MeCP2 expression by a CREB-induced microRNA. Nat Neurosci 10 (12):15131514

71. Hansen KF, Sakamoto K, Wayman GA, Impey S, Obrietan K (2010) Transgenic miR132 alters neuronal spine density and impairs novel object recognition memory. PLoS One 5 (11):e15497

72. Bijkerk R, Trimpert C, van Solingen C, de Bruin RG, Florijn BW, Kooijman S, van den Berg R, van der Veer EP, Bredewold EOW, Rensen PCN, Rabelink TJ, Humphreys BD, Deen PMT, van Zonneveld AJ (2018) MicroRNA-132 controls water homeostasis through regulating MECP2-mediated vasopressin synthesis. Am J Physiol Renal Physiol

73. Im HI, Kenny PJ (2012) MicroRNAs in neuronal function and dysfunction. Trends Neurosci 35 (5):325-334

74. Gan L, Denecke B (2013) Profiling Pre-MicroRNA and Mature MicroRNA Expressions Using a Single Microarray and Avoiding Separate Sample Preparation. Microarrays (Basel) 2 (1):24-33

75. Chandrasekar V, Dreyer JL (2009) microRNAs miR-124, let-7d and miR-181a regulate cocaine-induced plasticity. Mol Cell Neurosci 42 (4):350-362

76. Slezak-Prochazka I, Durmus S, Kroesen BJ, van den Berg A (2010) MicroRNAs, macrocontrol: regulation of miRNA processing. Rna 16 (6):1087-1095

77. Young JI, Hong EP, Castle JC, Crespo-Barreto J, Bowman AB, Rose MF, Kang D, Richman R, Johnson JM, Berget S, Zoghbi HY (2005) Regulation of RNA splicing by the methylation-dependent transcriptional repressor methyl-CpG binding protein 2. Proceedings of the National Academy of Sciences of the United States of America 102 (49):17551-17558

78. Cheng TL, Wang Z, Liao Q, Zhu Y, Zhou WH, Xu W, Qiu Z (2014) MeCP2 suppresses nuclear microRNA processing and dendritic growth by regulating the DGCR8/Drosha complex. Dev Cell 28 (5):547-560

79. Bayerlein K, Kraus T, Leinonen I, Pilniok D, Rotter A, Hofner B, Schwitulla J, Sperling W, Kornhuber J, Biermann T (2011) Orexin A expression and promoter methylation in patients with alcohol dependence comparing acute and protracted withdrawal. Alcohol 45 (6):541-547

80. Hayakawa K, Hirosawa M, Tabei Y, Arai D, Tanaka S, Murakami N, Yagi S, Shiota K (2013) Epigenetic switching by the metabolism-sensing factors in the generation of orexin neurons from mouse embryonic stem cells. J Biol Chem 288 (24):17099-17110

81. Dehan P, Canon C, Trooskens G, Rehli M, Munaut C, Van Criekinge W, Delvenne P (2013) Expression of type 2 orexin receptor in human endometrium and its epigenetic silencing in endometrial cancer. J Clin Endocrinol Metab 98 (4):1549-1557

82. Bramham CR, Wells DG (2007) Dendritic mRNA: transport, translation and function. Nat Rev Neurosci 8 (10):776-789. doi:10.1038/nrn2150

83. Baldo BA, Daniel RA, Berridge CW, Kelley AE (2003) Overlapping distributions of orexin/hypocretin- and dopamine-beta-hydroxylase immunoreactive fibers in rat brain regions mediating arousal, motivation, and stress. The Journal of comparative neurology 464 (2):220237 
84. Marcus JN, Elmquist JK (2006) Orexin Projections and Localization of Orexin Receptor. In: Nishino S, Sakurai $\mathrm{T}$ (eds) The Orexin/Hypocretin System Contemporary Clinical Neuroscience Humana Press, Chapter 3:21-44

85. Paxinos GW, C. (2007) The rat brain in stereotaxic coordinates. 6th edn

Academic Press, Elsevier

\section{Figures legends}

\section{Figure 1}

Cocaine and food pellets operant self-administration paradigm in FR5 schedule of reinforcement.

The effect of cocaine administration and food delivery was measured following a FR1 schedule of reinforcement for $4 \mathrm{~d}$ and then a FR5 schedule for $6 \mathrm{~d}(\mathrm{~A})$. The number of cocaine injections in self-administering rats and food pellets self-delivery during the FR5 schedule is depicted as black squares for food pellets delivery and white circles for cocaine administration (B). Similar circles and squares are used for the percentage of nose pokes in the active hole $(\mathrm{NPa})$ for food and cocaine (C). Data represent the mean ( $\mathrm{n}=8-12$ per group) with interexperimental variation not exceeding $10 \%$.

\section{Figure 2}

Dnmt3a and Dnmt3b mRNA expression in the prefrontal cortex (PFCx) and the caudate putamen $(\mathrm{CPu})$ in response to passive vs. voluntary cocaine, food pellets delivery and food restriction.

The effect of cocaine and food reward and that of operant conditioning on Dnmt3a (A, B) and $\operatorname{Dnmt3b}$ (C, D) level were evaluated by quantitative RT-PCR $24 \mathrm{~h}$ after the beginning of the last session of cocaine and food pellets administration in the PFCx $(\mathrm{A}, \mathrm{C})$ and in the $\mathrm{CPu}$ (B,D). Yoked control rats from the cocaine experiments that were not food restricted were compared with those from the food pellet experiments that were food restricted to check the food restriction effect. The effect of passive cocaine or food pellets intake was investigated by comparing either 'Yoked cocaine' to 'Yoked control' rats or 'Yoked pellets' to 'Yoked control' rats, whereas the effect of voluntary intake was evaluated by comparing either 'SA cocaine' to 'Yoked cocaine' rats or 'SA pellets' to 'Yoked pellets' rats. 'Yoked control' rats was compared to either 'SA cocaine' or 'SA pellets'. The amount of Dnmt3a and Dnmt3b transcript were normalized to that of $36 B 4$. Data represent the mean \pm S.E.M., $n=4-6$ per group (ABCD). Statistical analysis performed was one-way analysis of variance (ANOVA) followed by Newman-Keuls post-hoc, when required. ${ }^{*} \mathrm{p}<0.05, * * \mathrm{p}<0.01$.

\section{Figure 3}

Tet1, Tet2 and Tet 3 mRNA expression in the PFCx and the $\mathrm{CPu}$ in response to passive vs. voluntary cocaine or food pellets delivery.

The effects of cocaine and food reward and that of related operant conditioning on Tets' mRNA levels were evaluated by quantitative RT-PCR $24 \mathrm{~h}$ after the beginning of the last session of cocaine and food pellets administration in the PFCx $(\mathrm{A}, \mathrm{B}, \mathrm{C})$ and in the $\mathrm{CPu}(\mathrm{D}, \mathrm{E}$, F). Food restriction was measured by comparing yoked control rats from the cocaine experiments that were not food restricted with those from the food pellet experiments that were food restricted. Expression of the three genes was normalized to that of $36 B 4 \mathrm{mRNA}$. Data represent the mean \pm S.E.M., $n=4-6$ per group. Statistical analysis performed was one- 
way analysis of variance (ANOVA) followed by Newman-Keuls post-hoc, when required. $* \mathrm{p}<0.05, * * \mathrm{p}<0.01, * * * \mathrm{p}<0.001$.

\section{Figure 4}

Expression of primary miR-212/132 transcript (pri-miR-212/132) and its precursors in the prefrontal cortex $(\mathrm{PFCx})$ and the caudate putamen $(\mathrm{CPu})$ in response to passive vs. voluntary cocaine or food pellets delivery and to food restriction.

Quantitative RT-PCR was applied to evaluate the effects of cocaine and food reward and that of operant conditioning on pri-miR-212/132 (A, D), miR-212 (B, E) and miR-132 (C, F) level, $24 \mathrm{~h}$ after the beginning of the last session of cocaine and food pellets administration in the PFCx $(\mathrm{A}, \mathrm{B}, \mathrm{C})$ and in the $\mathrm{CPu}(\mathrm{D}, \mathrm{E}, \mathrm{F})$. Yoked $\mathrm{NaCl}$ rats from cocaine experiments that are not food restricted were compared to yoked controls from the food pellet experiments that were food restricted to measure the food restriction effect. The amount of pri-miR-212/132 transcript and its precursors were normalized to that of miR-U6 RNA. Data represent the mean \pm S.E.M., $n=4-6$ per group. Statistical analysis performed was one-way analysis of variance (ANOVA) followed by Newman-Keuls post-hoc, when required. $* \mathrm{p}<0.05$, $* * \mathrm{p}<0.01, * * * \mathrm{p}<0.001$.

\section{Figure 5}

Orexin receptor 1 DNA methylation and gene expression.

OrxRl gene methylation including location and number of differentially methylated regions and their patterns in cocaine self-administering and control rats are depicted in (A), consistent with genome wide DNA methylation analysis. Cocaine, food and food restriction effects on orxR1 mRNA levels were evaluated in the PFCx (B) and the $\mathrm{CPu}(\mathrm{C})$, as indicated in previous figures. Data represent the mean \pm S.E.M., $n=4-6$ per group. Statistical analysis performed was one-way analysis of variance (ANOVA) followed by Newman-Keuls post-hoc, when required. ${ }^{*} \mathrm{p}<0.05$.

\section{Figure 6}

Passive and voluntary cocaine or food pellets delivery effect on orexin mRNA and peptide expression in the lateral hypothalamus.

The effect of cocaine and food pellets on orexin peptide expression was evaluated by immunohistochemistry (A, B, C) and that of its mRNA was evaluated by RT-qPCR (D) in the LH. Representative immunostainings are shown for cocaine (A) and food pellets (B) experiments. The level of positive cells has been evaluated relative to nuclear Hoechst staining and the negative controls without primary antibody did not exhibit any significant signal. Food restriction effect (C, D) and normalization of mRNA levels (D) were measured, as in previous figures. Data represent the mean \pm S.E.M., $n=4-6$ per group. Statistical analysis performed was one-way ANOVA followed by Newman-Keuls post-hoc, when required. ${ }^{*} \mathrm{p}<0.05, * * \mathrm{p}<0.01$. Immunohistochemistry of ORX in the LH $(\mathrm{C}, \mathrm{D})$, scale bar applicable to all micrographs, $100 \mu \mathrm{M}$.

\section{Figure 7}

\section{Orexin mRNA expression in the CPu and the $\mathrm{LH}$}

Orx mRNAs in the $\mathrm{CPu}$ and the LH were analyzed by RT-qPCR by comparing their expression in yoked $\mathrm{NaCl} /$ control rats between both brain structures (A). In the $\mathrm{CPu}$, their expression was evaluated in cocaine (B), food pellets (C) and food restriction experiments (D). Data represent the mean \pm S.E.M., $n=4-6$ per group. Statistical analysis performed was one-way analysis of variance (ANOVA) followed by Newman-Keuls post-hoc, when required. $* \mathrm{p}<0.05, * * \mathrm{p}<0.01, * * * \mathrm{p}<0.001$. 


\section{Supplementary Figure 1}

\section{Dissected brain regions for $\mathrm{mRNA}$ analysis}

A. To dissect out the medial prefrontal cortex, including the cingulate cortex $(\mathrm{Cg} 1)$, the prelimbic cortex (PrL) and the infralimbic cortex (IL), a coronal slice was performed approximately at $2.70 \mathrm{~mm}$ anterior to bregma, as illustrated by the figure 9 of the atlas of Watson and Paxinos [85]. The medial part of the brain located medially to the corpus callosum was collected, as indicated by 2 rectangles. B. The caudate-putamen $(\mathrm{CPu}$ /shadowed areas) was dissected out from a $1.5 \mathrm{~mm}$ width coronal section beginning from the previous slice and ending approximately $1.2 \mathrm{~mm}$ anterior to the bregma, as illustrated by the figure 13 of the atlas of Watson and Paxinos. C. Hypothalamus was dissected from the rostral side $(\mathrm{C} 1)$ to the caudal side $(\mathrm{C} 2)$, as indicated by areas marked with a blue borderline.

\section{Supplementary Figure 2}

miR-212/132 gene cluster located on chromosome 10.

Rat $m i R-212$ (yellow) and $m i R-132$ (green) genes are shown, with locations of AP-1 binding site (Fos/Jun) (black) and CRE elements (pink). The position of $4 \mathrm{CpG}$ islands is indicated in light blue and that of primers are highlighted for pri-miR-212/132 (purple arrow), pre-miR212 (red arrow) and pre-miR-132 (blue arrow). Similar color codes were used in the DNA sequence of the cluster, as indicated.

\section{Supplementary table}

\section{Gene differentially methylated regions in the PFCx}

For each gene, DMRs identified in genome wide DNA methylation analysis are depicted with their numbers and their position relative to transcription start sites. The ratio of $5 \mathrm{mC}$

[cocaine]/[saline] are expressed as average and peak values together with mRNA expression indicated in bold. All ratio corresponding to hypomethylation $(<1)$ are highlighted in grey, as well the mean expression of genes induced by cocaine (ratio $>1$ ). The presence of $\mathrm{CpG}$ islands associated with DMRs is indicated by a red asterisk *. 


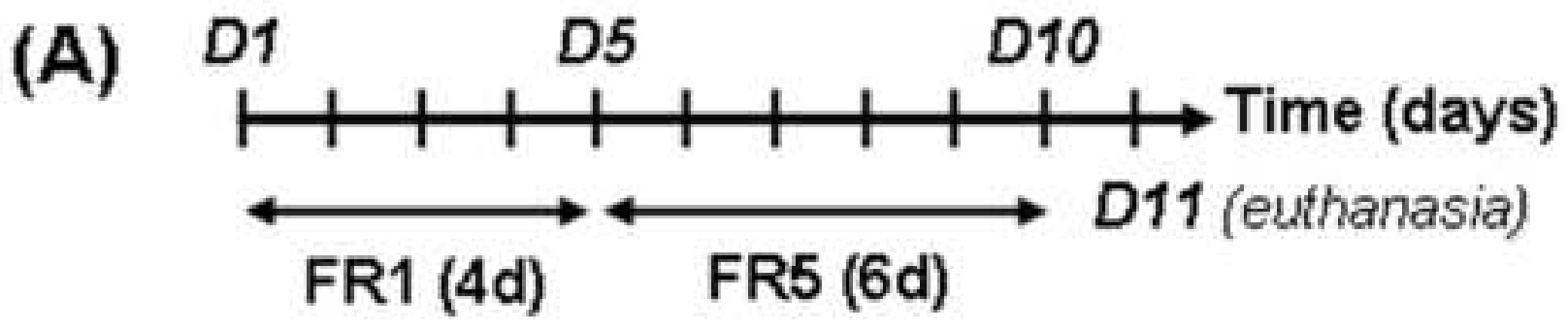

(B) Food self-delivery O Cocaine self-injections
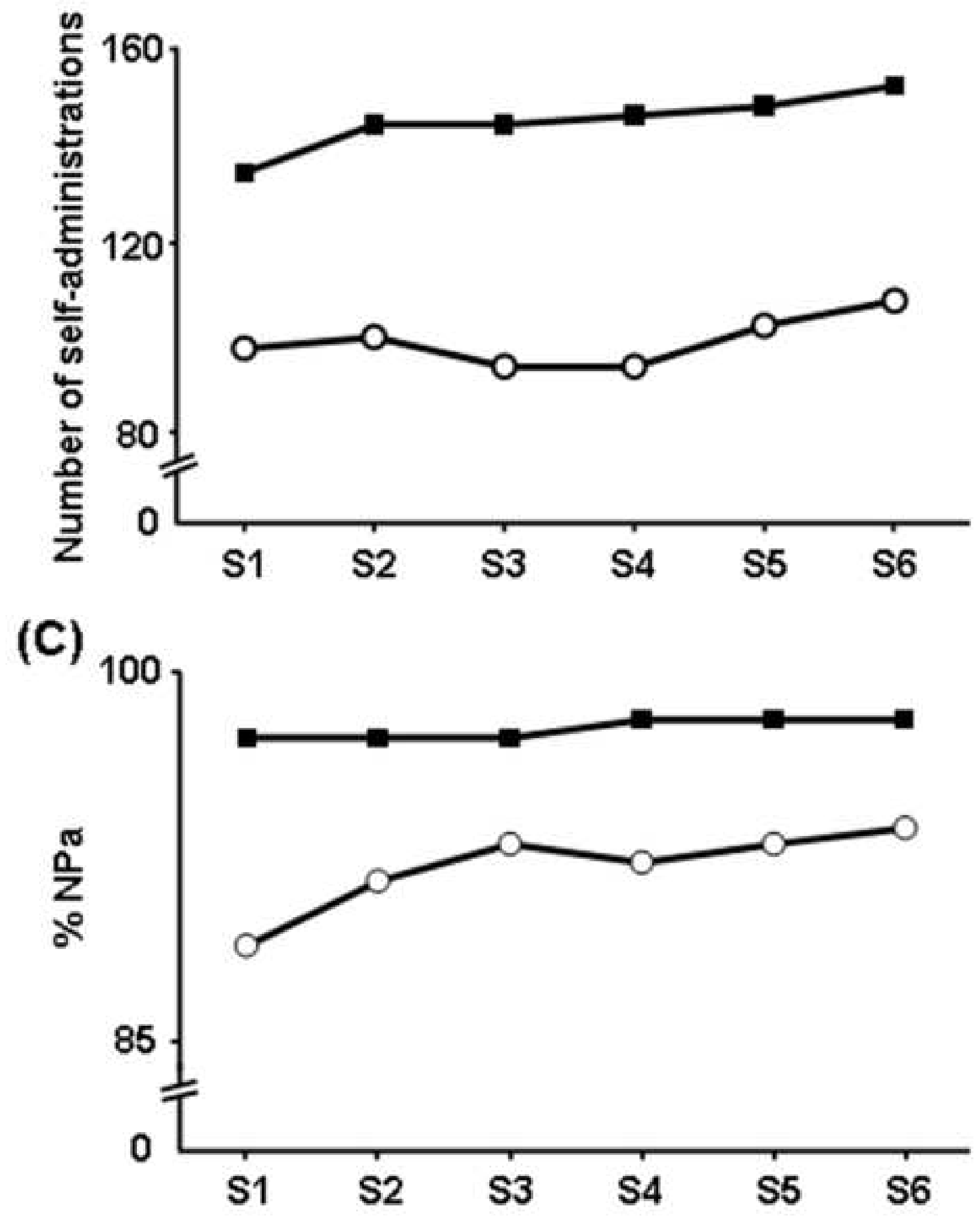


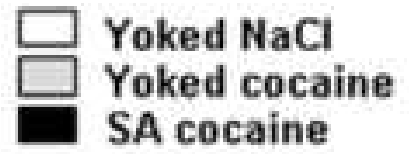

(A) PFCX

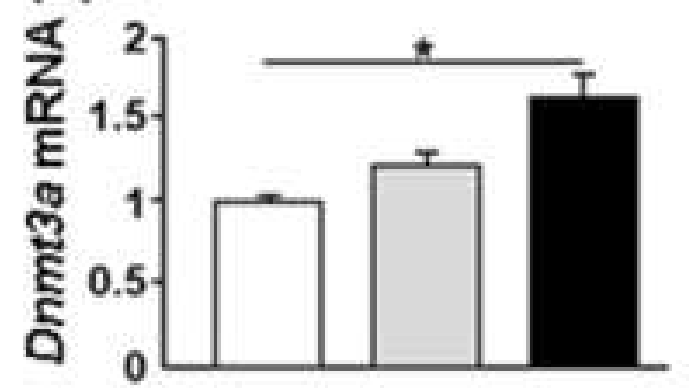

(B) $\mathrm{CPu}$

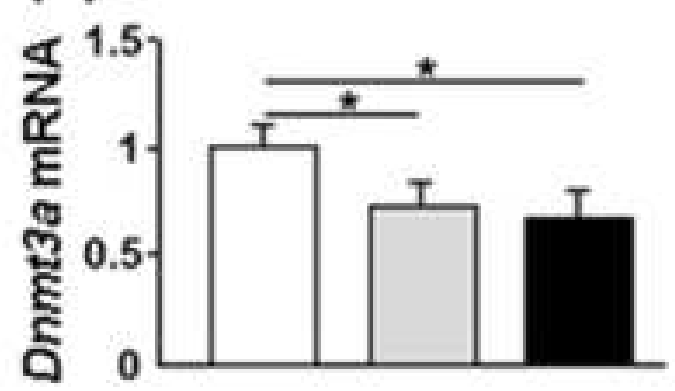

\section{(C) PFCX}

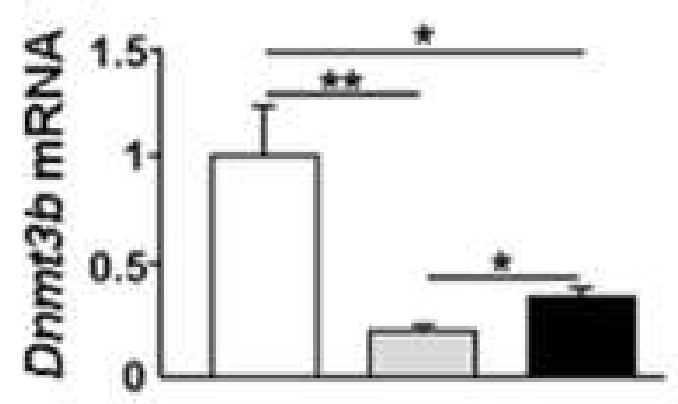

\section{(D) $\mathrm{CPu}$}

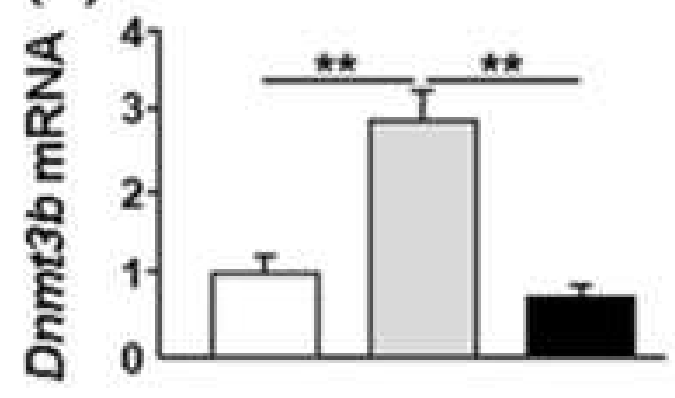

Yoked control

Yoked pellets

SA pellets
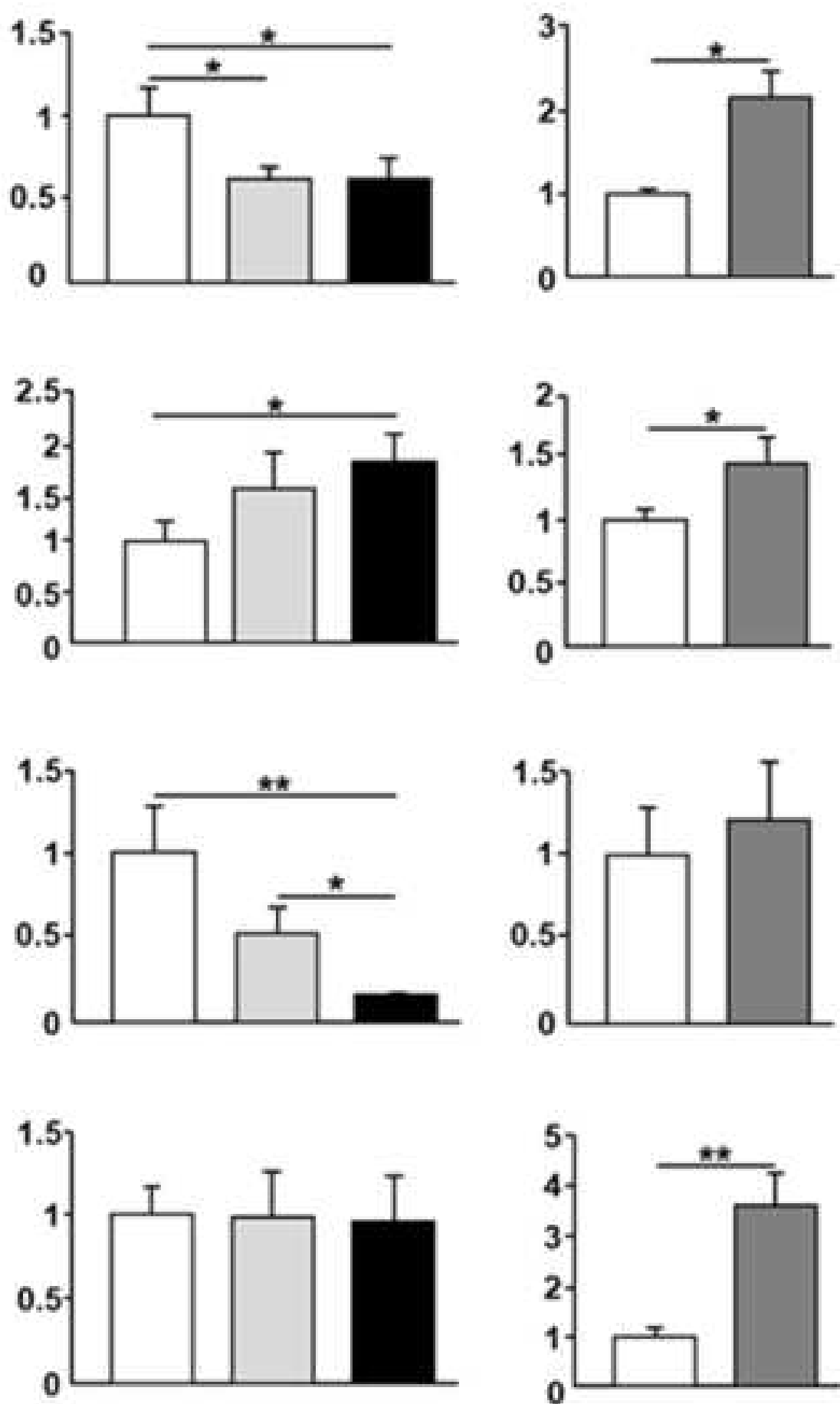

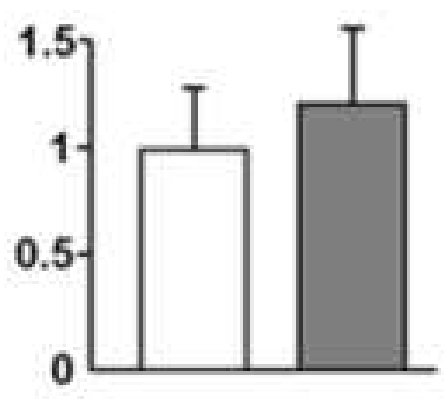

$\square$ ad libitum feeding

$\square$ Restricted feeding
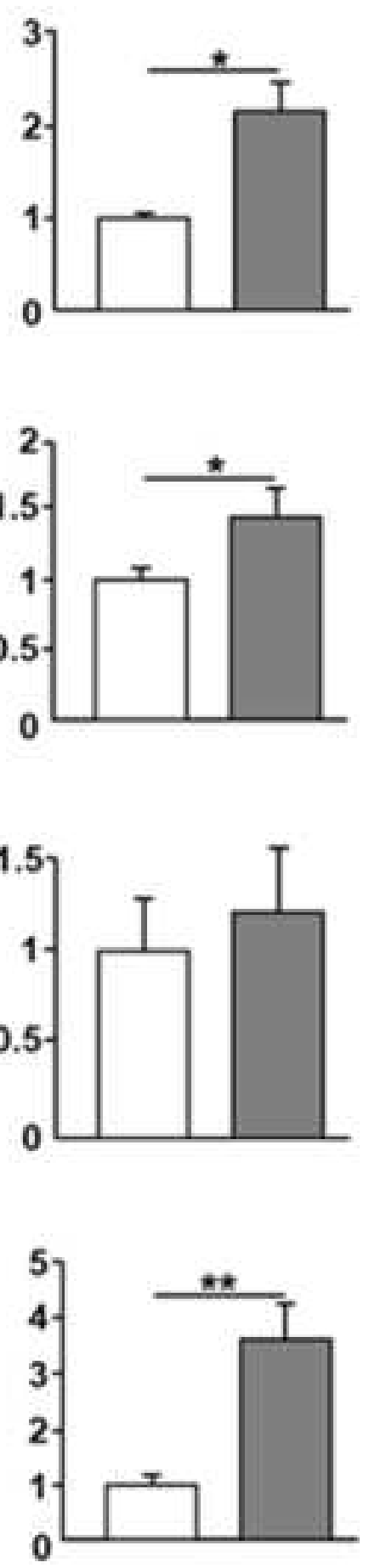


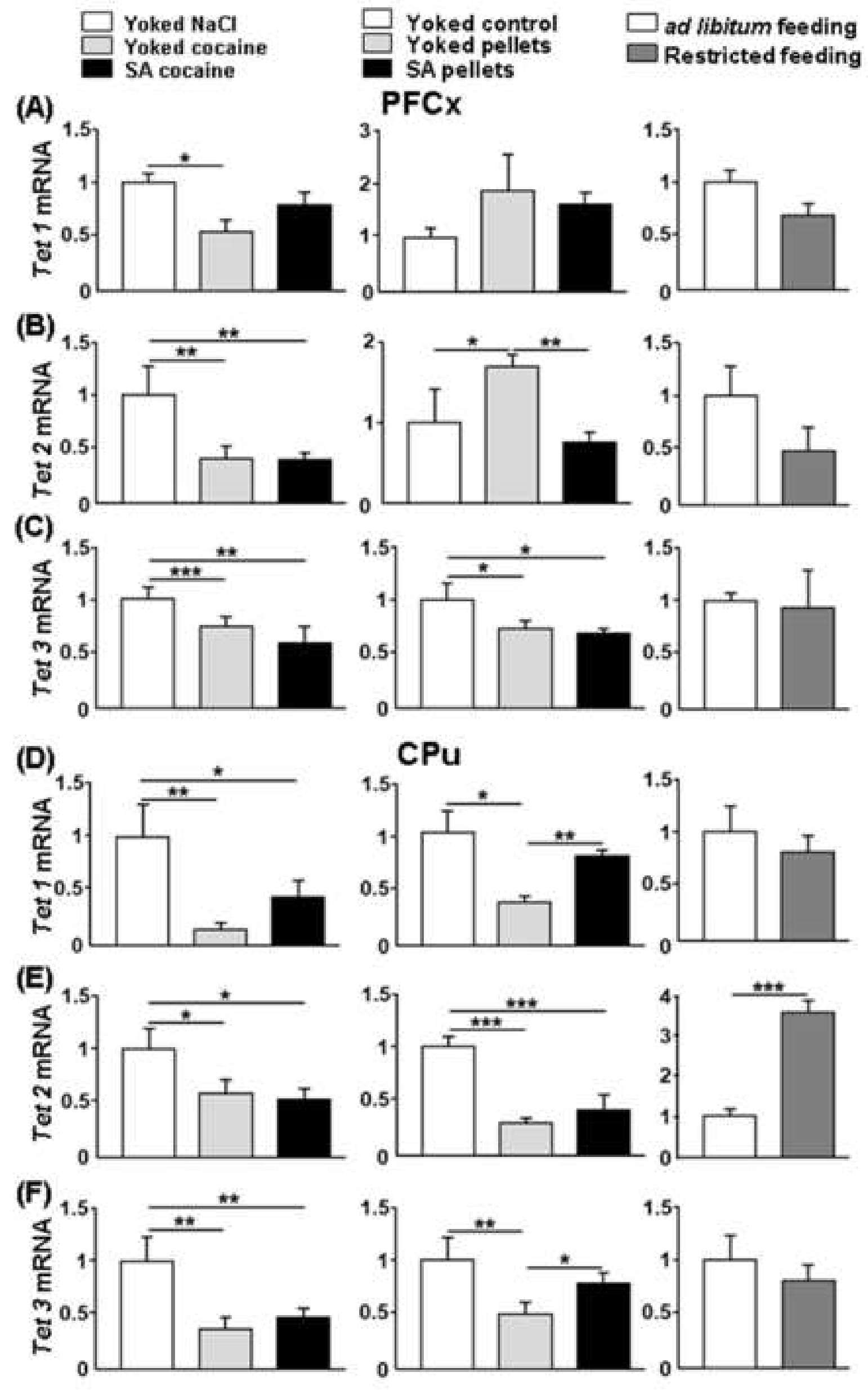




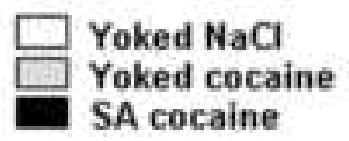

(A)

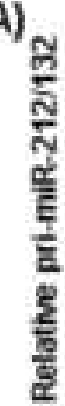

(B)

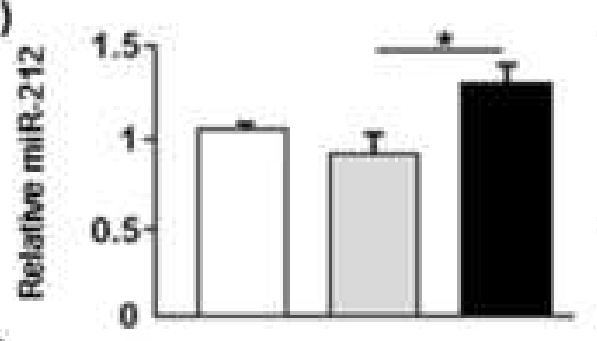

(C)

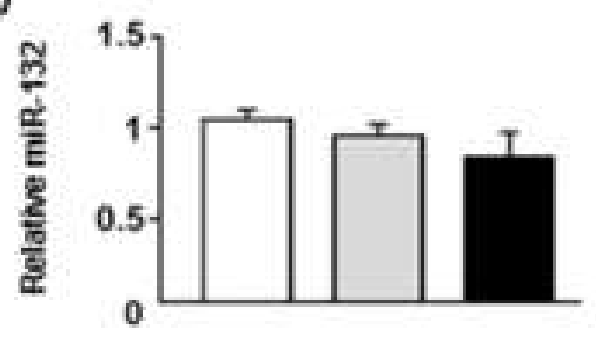

(D)

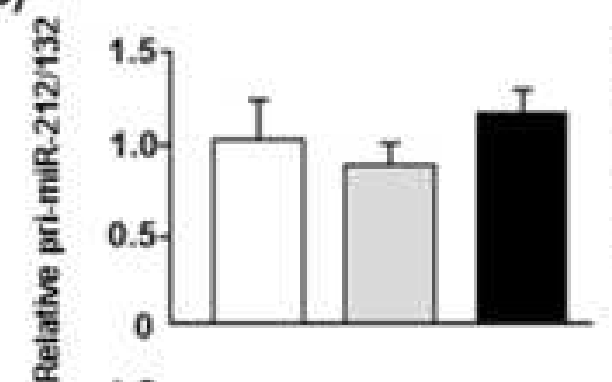

(E)

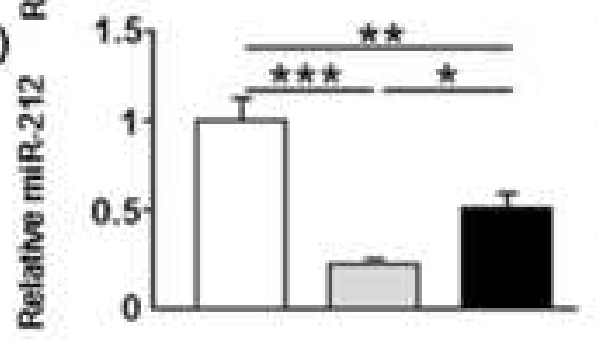

(F)

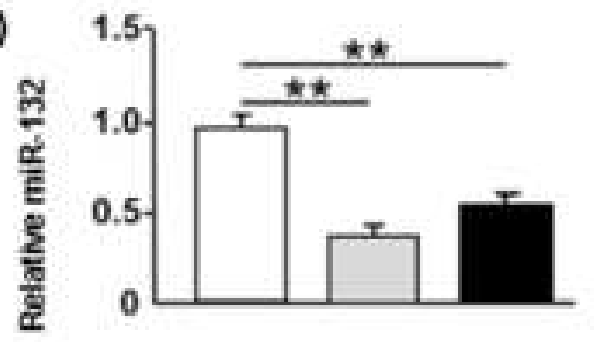

\section{PFCx}
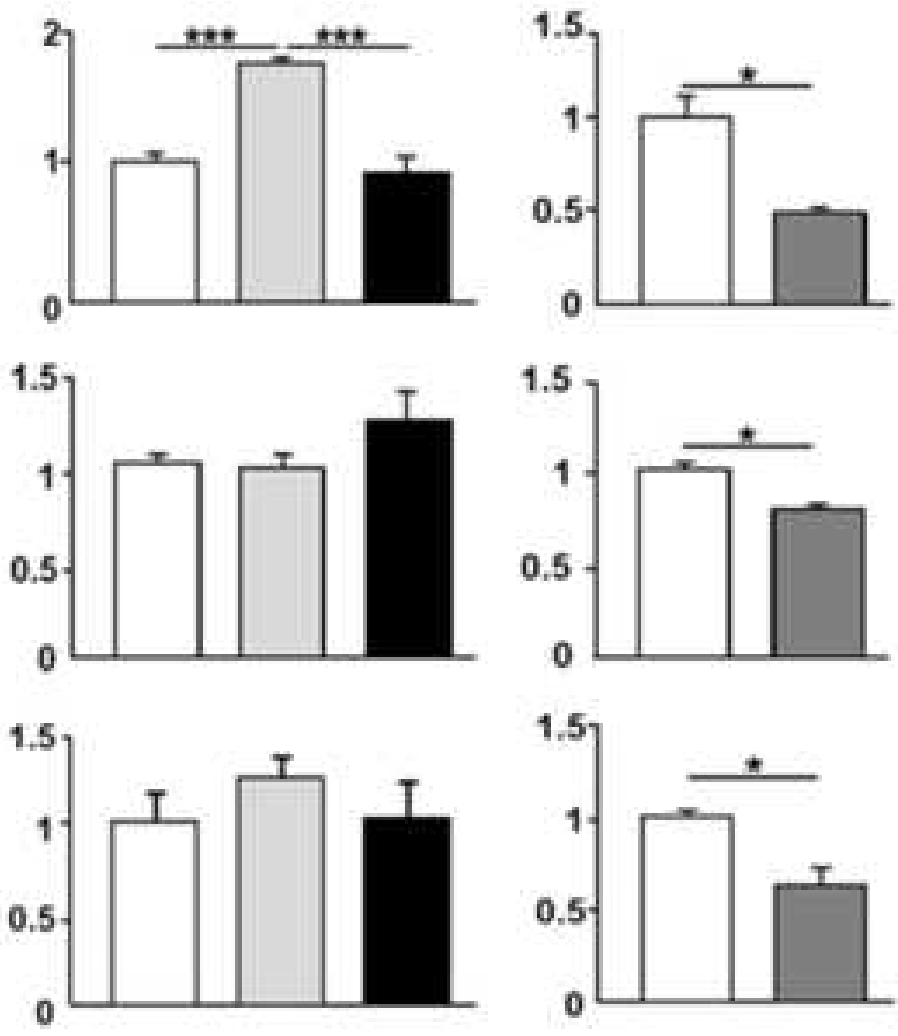

$\mathrm{CPu}$
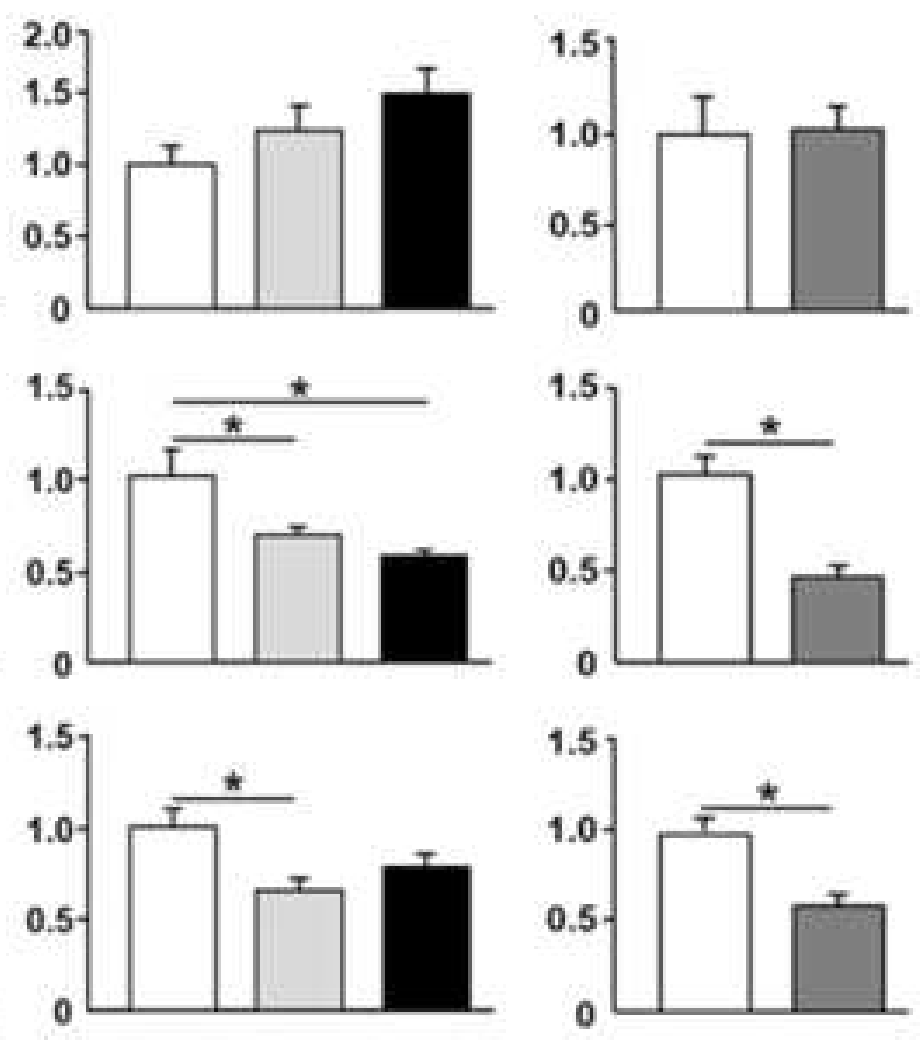


\section{(A) Orexin R1 gene Differentially Methylated Regions}

\begin{tabular}{lccc} 
Position & $\begin{array}{c}\text { Distance to start } \\
\text { (bp) }\end{array}$ & $\begin{array}{c}\text { Length } \\
\text { (bp) }\end{array}$ & $\begin{array}{c}5 \mathrm{mC} \\
\text { [Coc][NaC] }\end{array}$ \\
\hline upstream & -9935 & 1105 & 0.70 \\
& -8967 & 617 & 0.82 \\
& -7926 & 575 & 0.90 \\
\hline within gene & 6167 & 580 & 0.58 \\
(9.4 Kb) & 1776 & 478 & 0.51 \\
\hline downstream & 13706 & 582 & 0.70 \\
\hline
\end{tabular}

(B) $\square$ Yoked NaCl PFCX $\square$ Yoked cocaine

$\square$ Yoked control $\square$ Yoked peilets

$\square$ as ibsitum feeding PFCX sacocaino

\section{WA pellets}
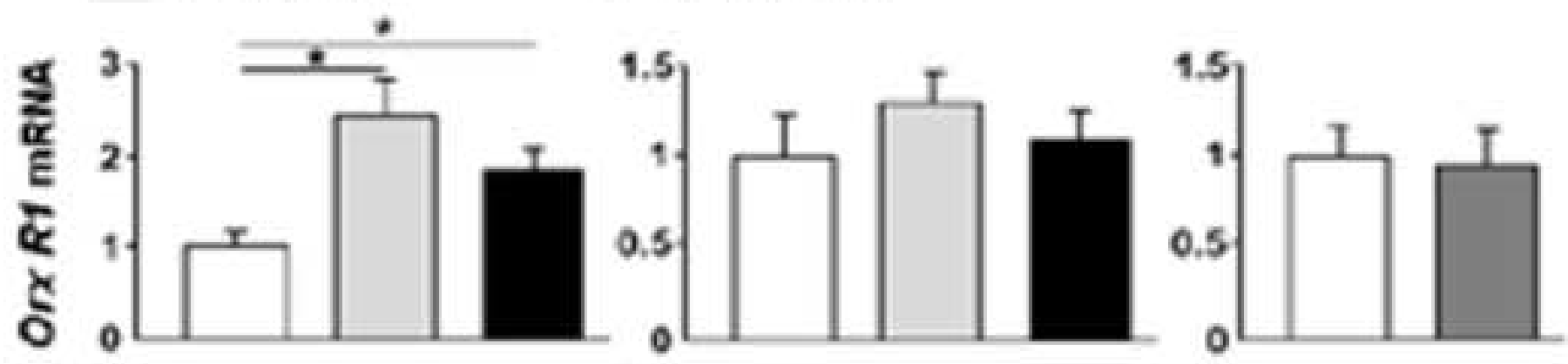

(C) $\mathrm{CPu}$
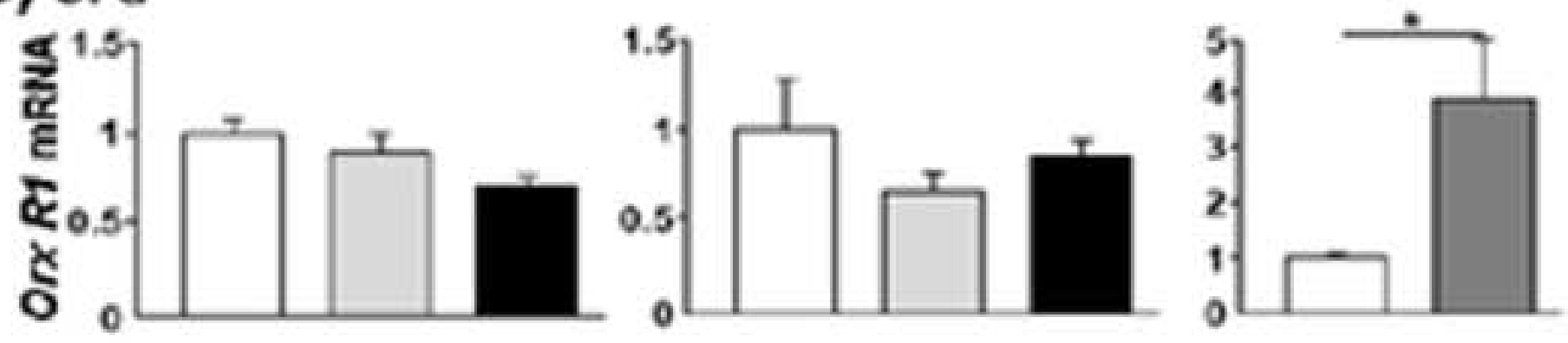


\section{(A) Yoked NaCl Yoked cocaine SA cocaine}

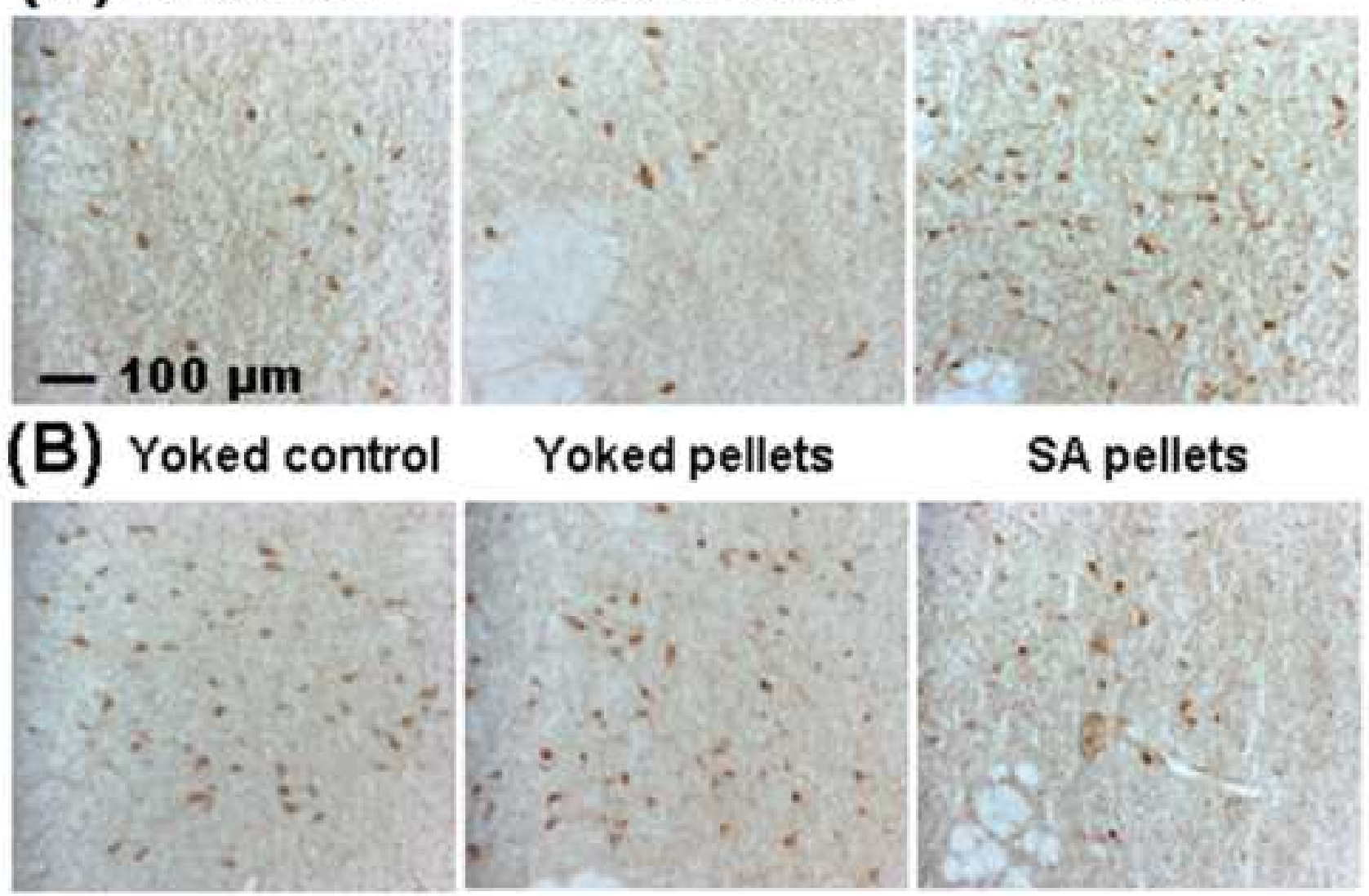

$\square$ Yoked $\mathrm{NaCl}$ $\square$ Yoked cocaine - SA cocaine $\square$ Yoked control $\square$ Yoked pellets - SA pellets

\section{(C) Orexin peptide}
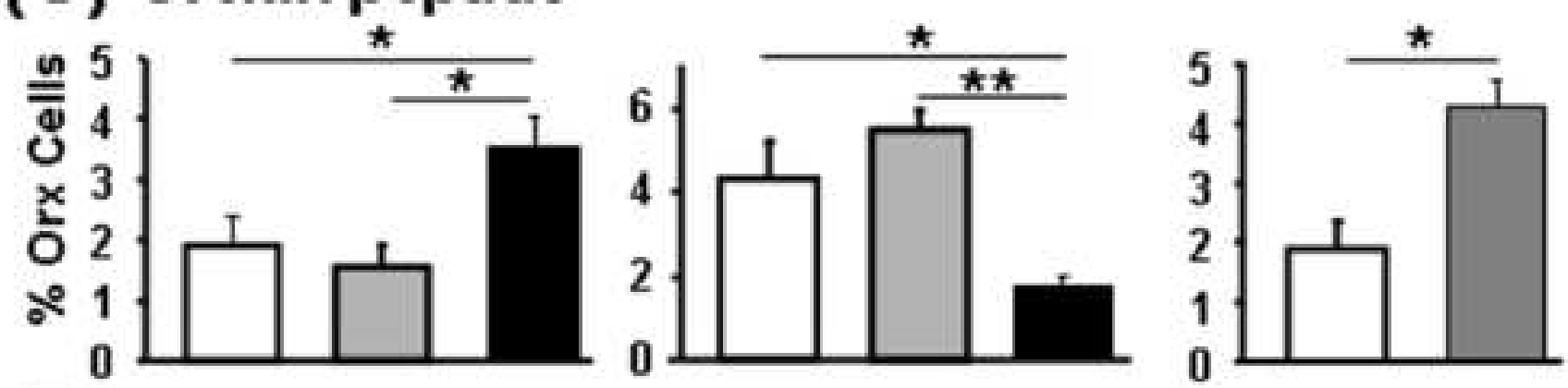

(D) Orexin mRNA
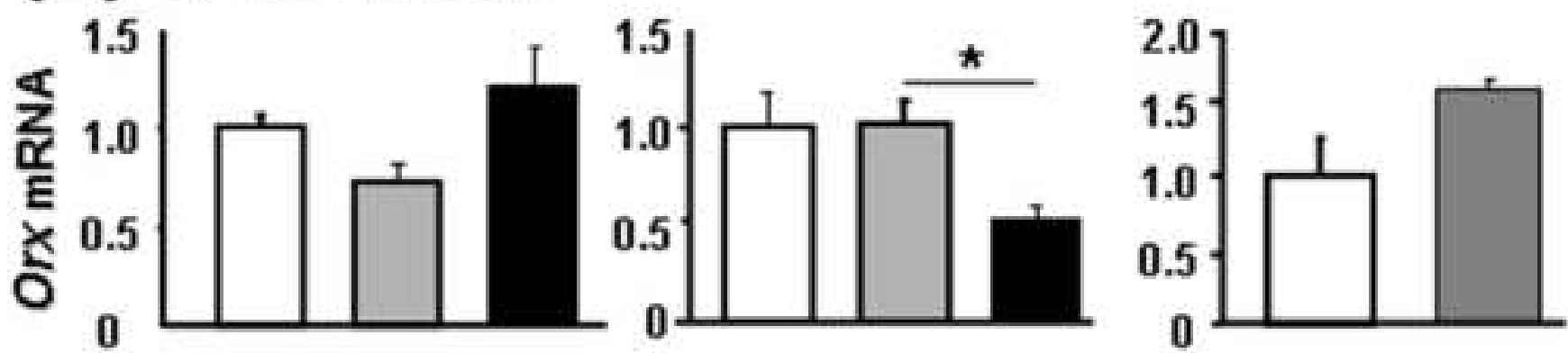


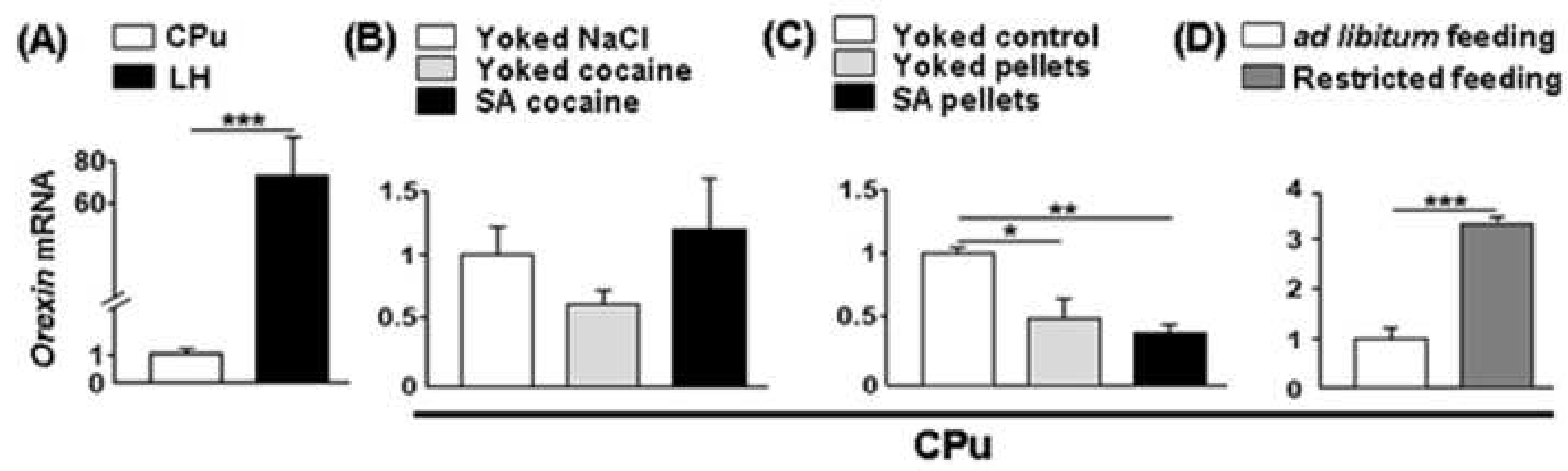
(A) $\square \mathrm{CPu}$
(B)
Yoked $\mathrm{NaC}$
oked cocaine
A cocaine

$\mathrm{CPu}$ 


\section{Table 1: Primer sequences}

\begin{tabular}{|c|c|c|}
\hline Gene & Primer sequence (5' - 3') & GeneBank Acc. \# \\
\hline \multirow{2}{*}{$M i R-212 / 132$} & FP:AAGGTCCCCGTGGGTTACA & \multirow{2}{*}{$\begin{array}{l}\text { AC_000078.1 from } \\
59053356 \text { to } 59053749\end{array}$} \\
\hline & RP:TCCGGTTCCCACAGTAACAA & \\
\hline \multirow[t]{2}{*}{$\operatorname{MiR}-212$} & FP:GGCACCTTGGCTCTAGACTG & \multirow[t]{2}{*}{ NR_031925.1 } \\
\hline & RP:GCCGTGACTGGAGACTGTTA & \\
\hline \multirow{2}{*}{$M i R-132$} & FP:ACCGTGGCTTTCGATTGTTA & \multirow{2}{*}{ NR_031878.1 } \\
\hline & RP:GGCGACCATGGCTGTAGACT & \\
\hline \multirow{2}{*}{$M i R-U 6$} & FP:CTTCGGCAGCACATATACTAAAA & \multirow{2}{*}{ K00784.1 } \\
\hline & RP:GAATTTGCGTGTCATCCTTG & \\
\hline \multirow{2}{*}{$D n m t 3 A$} & FP:GCTGAAGGAGAGGGAACTGA & \multirow{2}{*}{ NM_001003958 } \\
\hline & RP:TGCCTGGAAGGTGAGTCTTG & \\
\hline \multirow{2}{*}{$D n m t 3 B$} & FP:TGCGGTAAGAAGAACCCTGT & \multirow{2}{*}{ NM_001003959 } \\
\hline & RP:CTGATAGCCGTCCTCATCGT & \\
\hline \multirow{2}{*}{ Tet } & CTGTGGGGAATGCACCTACT & \multirow{2}{*}{ XM_008774952.1 } \\
\hline & TGGCTTCTTTTTGAGCACCT & \\
\hline \multirow{2}{*}{ Tet2 } & AGAAGCG TAAGAAG CG CAGT & \multirow{2}{*}{ XM_006224264.2 } \\
\hline & TCTTTTTCATTTGACCGTCTCTTCC & \\
\hline Tet3 & $\begin{array}{l}\text { TGTGTGCAAGAGGACTTTCG } \\
\text { TACTGACGGGTGTTTCTCC }\end{array}$ & XM_006224966 \\
\hline \multirow{2}{*}{ Orx } & TCCTTGGGTATTTGGACCAC & \multirow{2}{*}{ NM_013179 } \\
\hline & CCCAGGGAACCTTTGTAGAAG & \\
\hline \multirow[t]{2}{*}{ Orx $R I$} & CCATCAGTGTCCTCAATGTCC & \multirow[t]{2}{*}{ NM_013064.1 } \\
\hline & AGAAGGTGAAGCAGGCGTAG & \\
\hline $36 B 4$ & $\begin{array}{l}\text { CTGCCCGAGCCGGTGCCATC } \\
\text { TTCAATGGTACCTCTGGAGAT }\end{array}$ & NM_022402 \\
\hline
\end{tabular}

